\title{
anu \\ Optimizing the Synthesis and Thermal Properties of Conducting Polymer-Montmorillonite Clay Nanocomposites
}

\author{
Yanrong Zhu ${ }^{1}$, Jude O. Iroh ${ }^{1, *} \mathbb{B}$, Ramakrishnan Rajagopolan ${ }^{1}$, Aydin Aykanat ${ }^{1}$ and Richard Vaia ${ }^{2}$ \\ 1 Materials Science and Engineering Program, Department of Mechanical and Materials Engineering, \\ University of Cincinnati, Cincinnati, OH 45221, USA; yanrong_zhu2021@163.com (Y.Z.); \\ rur12@psu.edu (R.R.); aydin.aykanat@gmail.com (A.A.) \\ 2 Air Force Research Laboratory, Wright Patterson AFB, Dayton, OH 45433, USA; richard.vaia@us.af.mil \\ * Correspondence: irohj@ucmail.uc.edu
}

check for updates

Citation: Zhu, Y.; Iroh, J.O.;

Rajagopolan, R.; Aykanat, A.; Vaia, R. Optimizing the Synthesis and Thermal Properties of Conducting Polymer-Montmorillonite Clay Nanocomposites. Energies 2022, 15, 1291. https://doi.org/10.3390/ en15041291

Academic Editor: Carlos

Miguel Costa

Received: 18 December 2021

Accepted: 28 January 2022

Published: 10 February 2022

Publisher's Note: MDPI stays neutral with regard to jurisdictional claims in published maps and institutional affiliations.

Copyright: () 2022 by the authors Licensee MDPI, Basel, Switzerland. This article is an open access article distributed under the terms and conditions of the Creative Commons Attribution (CC BY) license (https:// creativecommons.org/licenses/by/ $4.0 /)$.

\begin{abstract}
Given the availability of a wide range of properties not possessed by individual materials, nanocomposites based on conducting polymers and inorganic materials have attracted much deserved attention. However, there has been little attempt to optimize the synthesis and thermal properties of polyaniline-clay nanocomposites. In this study, the synthesis and thermal properties of polyaniline (PANi) and polyaniline-clay nanocomposites (PACN) were performed by systematically varying the feed composition. Both PANi and polyaniline-montmorillonite (MMT) nanocomposites were prepared by using ammonium persulfate (APS) as the oxidant. The chemical structure of the nanocomposites was studied by Fourier transform infrared spectroscopy (FTIR). FTIR spectra confirmed the presence of clay in the nanocomposites and the existence of mainly the emiraldine form of PANi. Thermal analysis was performed by using thermogravimetric analysis (TGA) and differential scanning calorimetry (DSC). The morphology and structure of PANi and PACN were studied by scanning electron microscopy (SEM), wide-angle X-ray diffraction (WAXD), and transmission electron microscopy (TEM). Our results confirm the intercalation and partial exfoliation of clay. This study also showed that increasing the oxidant concentration resulted in decreasing thermal stability and melting temperature of PANi. The reinforcement of PANi with MMT resulted in increased thermal stability and increased melting point of PANi. It was also shown that the addition of only about $0.1 \mathrm{wt} \%$ of APS resulted in an optimal thermal stability and melting point for PANi.
\end{abstract}

Keywords: conducting polymers; nanocomposites; montmorillonite clay; polyaniline

\section{Introduction}

In recent years, there has been an upsurge in research interests in the synthesis of nanocomposites constituted of inorganic clay and an organic polymer matrix on a nanometer scale. It was found that the incorporation of the nano-sized clay fillers into an organic polymer matrix resulted in remarkable improvement in strength, modulus, thermal stability, electrical and dielectric properties, and fire retardant ability and decreased permeability of the nanocomposites [1-3]. A dramatic enhancement in properties is gained from a moderate clay loading of about $2 \mathrm{vol} \%$. Giannelis and his group reported that the combination of the polymer matrix and clay reinforcement resulted in the formation of nanocomposite by melt processing [4-6]. Since then, tremendous work has been done using the concept of organic-inorganic nanocomposite, based on clay and other polymer matrices, such as epoxy resins [7-9], polyamides [10-12], polyimides [13,14], polyurethane [15], and polypropylene [16]. In the recent years, the breakthrough advancement of nanotechnology has inspired people to combine clay with another special class of matrix materials known as the intrinsically conducting polymers (ICPs) to form ICP-clay nanocomposites [17].

Polyaniline belongs to the special class of intrinsically conducting polymers, ICPs, which, due to the presence of conjugated double bonds in their backbone, display unusually 
high electrical conductivity upon doping. Polyaniline (PANi) can exist in different oxidation states (see Figure 1) and is one of the most widely studied conducting polymers because of its environmental and chemical stability. Due to the excellent electrical and electronic properties and plastic nature of polyaniline (PANi), it has been proposed for a wide range of applications, such as antistatic coatings, electrochromic display, sensors, light-emitting diodes, capacitors, lightweight batteries, and gas permeation membranes. The combination of PANi with montmorillonite clay at the nanometer level may provide improved physical properties and enhanced chemical stability and may result in synergistic properties that are not possessed by the individual materials $[18,19]$.

\section{Emeraldine $(y=0.5)$}

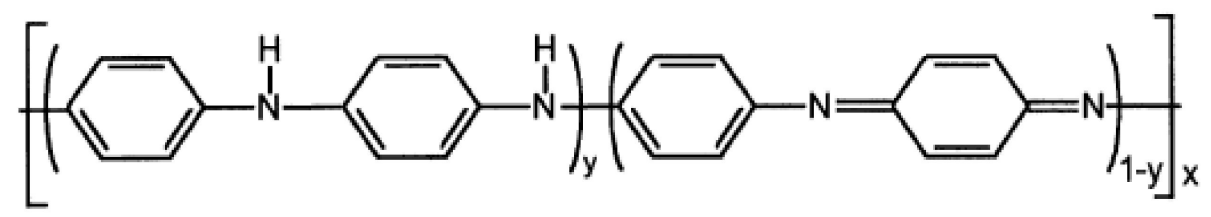<smiles></smiles>

\section{Pernigraniline}

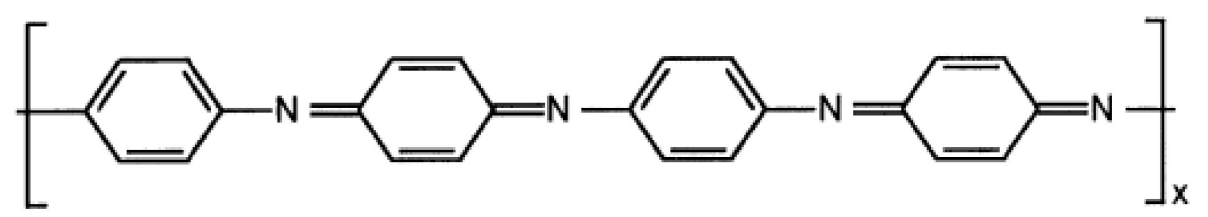

Figure 1. Structures of polyaniline at different oxidation states.

Layered silicate clays, especially smectite clays, are an interesting class of filler materials. Among the di-octahedral smectites, montmorillonite (MMT) is the most commonly used and relatively more abundant in nature. MMT is usually used as a sorbent of organic compounds, mainly because of its large surface area $\left(760 \times 10^{3} \mathrm{~m}^{2} / \mathrm{kg}\right)$, its high cation exchange capacity ( $\sim 1 \mathrm{~mol} \mathrm{~kg}^{-1}$ molar monovalent cations), and relative ease of forming an interlayer complex with a wide variety of organic molecules [20]. Due to the above advantages of MMT, it is a favorable candidate for reinforcing organic polymer materials.

The chemical formula of MMT is $(\mathrm{Na}, \mathrm{Ca})(\mathrm{Al}, \mathrm{Mg})_{6}\left(\mathrm{Si}_{4} \mathrm{O}_{10}\right)_{3}(\mathrm{OH})_{6}-\mathrm{nH}_{2} \mathrm{O}$. MMT belongs to the structural family known as 2:1 phyllosilicates. It is composed of layers of crystals stacked together periodically. The crystal structure usually consists of layers made up of two silica tetrahedral sheets sandwiching an octahedral sheet of either alumina or magnesia in which oxygen atoms are shared between the octahedral sheet and the silica tetrahedral sheet (See Figure 2a). Isomorphic replacement of trivalent metal ions (i.e., $\mathrm{Al}^{3+}$ ) by bivalent ions (i.e., $\mathrm{Mg}^{2+}$ ) within the layers causes a permanent net negative charge. The positive charge deficiency is usually balanced by the insertion of cations such as $\mathrm{Ca}^{2+}$ or $\mathrm{Na}^{+}$inside the galleries. The layers of clay align themselves in a parallel manner, form stacks, and are attracted to each other by a weak van de Waals force. The gap between the layers is called a gallery, and the distance (called $\mathrm{d}_{(001)}$ ) spacing can vary over a wide range depending on the size of the cations adsorbed. 


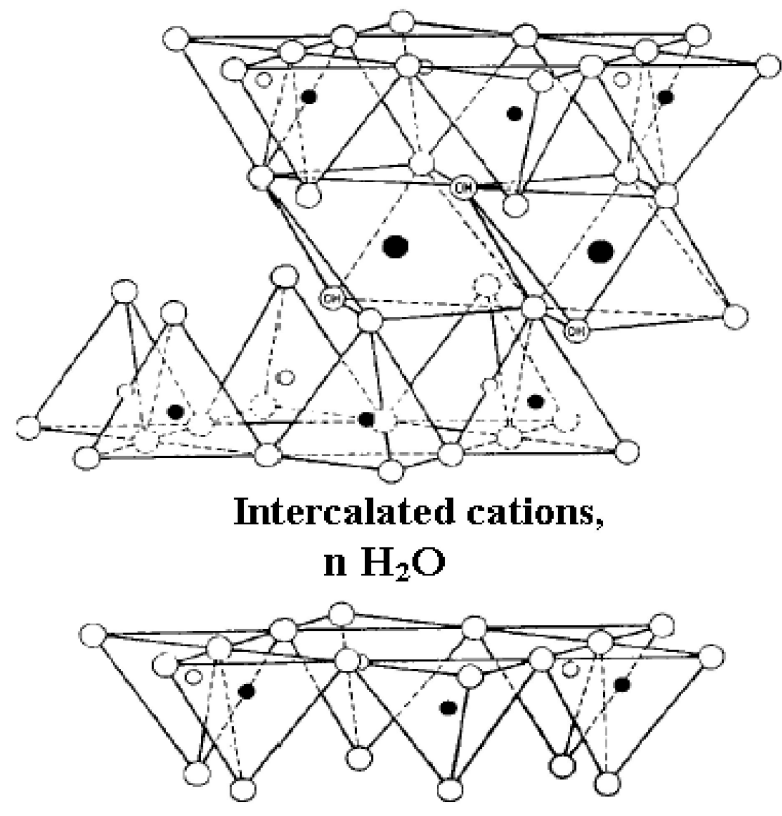

Oxygen $@$ Hydroxyls

$\circ$ and $\bullet$ Silicon, occasionally aluminum

\section{Aluminum, magnisium ions}

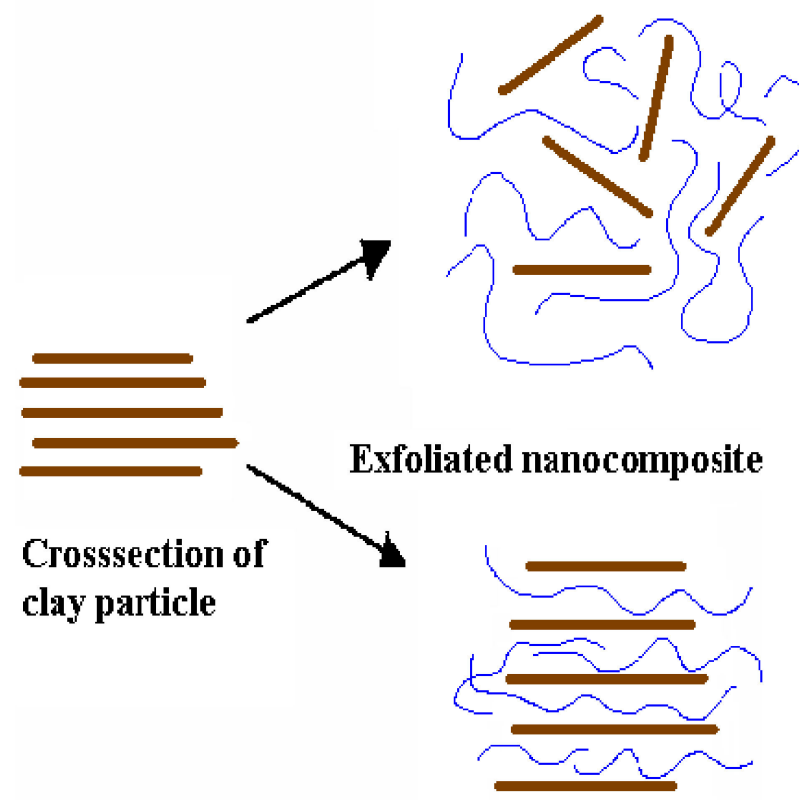

Intercalated nanocomposite

Figure 2. Crystallographic structure of the clay layer (a) and schematic view of nanocomposites formed with polymer (b).

Pristine clay is hydrophilic; thus, surfactants containing organo-ammonium ions are usually used to modify it by ion-exchange reaction with $\mathrm{Na}^{+}$or $\mathrm{Ca}^{2+}$ and thereby impart clay with hydrophobicity. The modified clay is called organoclay, and it is more compatible with organic polymer matrices and also easier to intercalate or exfoliate. Thus, it is preferred for forming polymer-clay nanocomposites. It can be either intercalated or exfoliated in a polymer matrix to form polymer nanocomposites (See Figure 2b). Due to its special layered structure and high aspect ratio, clay may impart the nanocomposites with improved mechanical and interfacial properties. The interaction between the organic and inorganic components is important, and it controls the ultimate properties of the nanocomposite materials.

The area of conducting polymer-clay nanocomposites represents an exciting trend in materials science in that it has vast potential applications due to the special nature of both components. Conducting polymers themselves could find their niche in every possible materials application. By overcoming their imperfections, incorporation of nano-platelets of clay provides a possibility of realizing commercialization of all of the suggested applications.

There have been reports of ICP-clay nanocomposites in recent years, mostly focusing on either polyaniline or polypyrrole (PPy). ICP-clay nanocomposites can be synthesized by two main ways, including chemical and electrochemical methods. Simultaneous electrophoretic deposition of PANi and clay has also been reported [21]. Most of the work on the synthesis of ICP-clay nanocomposites is done using the chemical method. Kim and colleagues [22] used an inverted emulsion pathway method to intercalate PPy into $\mathrm{Na}^{+}$MMT. Wu et al. [23] synthesized PANi-clay nanocomposites with extended chain conformation of polyaniline. Their composites showed a slight decrease in conductivity as compared with pure polyaniline. Kim and colleagues [24] also reported emulsionintercalated polyaniline-clay nanocomposites, and they reported that incorporation of 
clay interrupted the doping process and, thus, resulted in lower conductivity. Several other groups have synthesized PANi-clay nanocomposites [25-30]. Among these groups, Yeh and colleagues used PANi-MMT nanocomposites for corrosion protection for cold rolled steel [26]. They reported significant improvement in corrosion resistance of the PANi coating on CRS with incorporation of clay. There are reports by other groups that formulated PANi- $\mathrm{Na}^{+} \mathrm{MMT}$ suspensions with interesting electrorheological properties [31-33]. Other properties, such as thermal, mechanical, and gas barrier, also showed apparent enhancement at relatively low clay loading. However, there has not been a systematic study of the synthesis conditions and the associated structural and property changes of PANi-clay nanocomposites.

There is still no thorough understanding of the nature of PANi in the nanocomposites, and the interaction between the organic and inorganic component is not fully understood. In this paper, we successfully developed an approach to synthesize polyaniline-clay nanocomposites, PACN, based on PANi and MMT clay, and the structure and thermal properties of the resulting nanocomposite were controlled by systematically varying the synthesis conditions. Using advanced analytical techniques, such as FTIR, XRD, TEM, SEM, TGA, and DSC, we studied the structure of the resulting composites and determined the effect of synthesis conditions on the materials formed. This work aims at providing a systematic study of PACNs and shedding light on the interaction between PANi and clay fillers.

\section{Materials and Methods}

\subsection{Materials}

Aniline, N-methyl-2-pyrrolidinone (NMP), and ammonium persulfate (APS) were purchased from Aldrich Chemical Company Inc., Burlington, MA, USA and used as received. Cloisite ${ }^{\circledR}$ (Chicago, IL, USA) clay was purchased from Southern Clay Product Inc., Chicago, IL, USA.

\subsection{Preparation of the Powder Samples}

An appropriate amount of aniline was dissolved in distilled water. Then, clay was added into the solution under vigorous magnetic stirring for $2 \mathrm{~h}$. While clay was well dispersed in the solution using an ultrasonic bath, ammonium persulfate $\left(\left(\mathrm{NH}_{4}\right)_{2} \mathrm{~S}_{2} \mathrm{O}_{8}\right)$ dissolved in water was added dropwise. The mixture was magnetically stirred for $48 \mathrm{~h}$ before filtration. The filtrate was rinsed with $1000 \mathrm{~mL}$ distilled water. The obtained composites were dried in an oven under vacuum at $100{ }^{\circ} \mathrm{C}$. The composites were then ground, weighed, and stored in vials for later use.

In order to determine the effect of the oxidant on the nature and properties of the nanocomposites, various concentrations of ammonium persulfate were used in the synthesis of PANi. Different concentrations of clay were also used in the synthesis of the nanocomposites in order to study the effect of the percentage of clay on the structure and properties of the PACN.

\subsection{Characterization}

Samples were analyzed by Fourier transform infrared spectroscopy (FTIR) using a BioRad FTS-40 FTIR spectrometer (Bio-rad, Richmond, CA, USA). FTIR was used to determine the composition and structure of the nanocomposites. FTIR spectra were collected at a resolution of $4 \mathrm{~cm}^{-1}$ and averaged over 256 scans. The incident angle was set at the angle of $50^{\circ}$ for all of the samples. Powders were made into pellets using a hydraulic press by mixing $95 \mathrm{vol} \%$ of $\mathrm{KBr}$ and $5 \mathrm{vol} \%$ of the nanocomposites. A background spectrum of pure $\mathrm{KBr}$ pellet was subtracted from the collected spectra.

The thermal behavior of the nanocomposite powders was studied by using thermal gravimetric analysis (TGA) and differential scanning calorimetry (DSC). A heating rate of $10^{\circ} \mathrm{C} / \mathrm{min}$. was used. Both DSC and TGA were performed under nitrogen atmosphere in the temperature ranges of $25-400{ }^{\circ} \mathrm{C}$ and $25-800{ }^{\circ} \mathrm{C}$, respectively. 
X-ray diffraction $(X R D)$ patterns were obtained using a Philips $X^{\prime}$ pert Diffractometer with $\mathrm{Cu}-\mathrm{K} \alpha$ radiation source $(\lambda=1.54 \AA)$. The powder samples for XRD were prepared by dispersing a thin layer of the powder on a double-sided tape attached on a glass slide. The diffractometer was operated at $30 \mathrm{KV}$ and $25 \mathrm{~mA}$, and a scanning step of $0.05^{\circ}$ in two theta and a dwell time of $1 \mathrm{~s}$ were used. Part of the $\mathrm{X}$-ray diffraction measurements were carried out with a rotating anode X-ray generator (RU-200 BH, Rigaku-Rotaflex, $20 \mathrm{KV}$, $50 \mathrm{~mA}$ ). The powder samples were pressed into pellets for the experiments. Silver behenate standard was used for calibration.

The morphology of the nanocomposites was observed under the scanning electron microscope (SEM) using a Hitachi S-900 SEM. Transmission electron microscopy (TEM) was employed to study the structure of the PANi-clay nanocomposites using a Jeol JEM-2000 FX Electron Microscope.

\section{Results}

\subsection{Composition}

Infrared spectroscopy is a convenient technique, and it is widely used to analyze polyaniline-clay nanocomposites (PACN). It is especially useful for determining the oxidation states of conducting polymers. In this work, we studied the effect of oxidant concentration on the resulting PANi and PACN, since the amount of oxidant is the condition that most affects their structure.

PANi synthesized by in situ polymerization showed typical emeraldine form structure (Figure 1). The characteristic PANi absorption bands occur at 3265 and 3200 (doublet), as well as at 1584, 1512, 1300, 856, and 864 (doublet) $\mathrm{cm}^{-1}$ (Figure $3 \mathrm{~b}$ ). These peaks are due to the secondary amine, $\mathrm{C}=\mathrm{N}$ stretching, $\mathrm{C}-\mathrm{N}$ stretching, $\mathrm{N}-\mathrm{H}$ deformation, and $\mathrm{p}$-substituted benzene ring hydrogen, respectively. Organically modified MMT clay CLOISITE ${ }^{\circledR} 20$ A contains quaternary ammonium salt in the gallery, and the structure of the cation is shown in Figure 3a. The characteristic FTIR spectrum of 20 A shows a doublet at 2854 and $2928 \mathrm{~cm}^{-1}$ due to the presence of $-\mathrm{CH}_{2}-$ group; a broad peak at $1054 \mathrm{~cm}^{-1}$ corresponds to $\mathrm{Si}-\mathrm{O}$ stretching; and another doublet at $450-600 \mathrm{~cm}^{-1}$ was assigned to silicate $\mathrm{Si}-\mathrm{O}$ bond bending and $\mathrm{Al}-\mathrm{O}$ stretching (Figure $3 \mathrm{~b}$ ). Detailed assignment of the peaks of both PANi and CLOISITE ${ }^{\circledR} 20$ A clay is shown in Tables 1 and 2. The FTIR spectra for PANi, CLOISITE $^{\circledR} 20 \mathrm{~A}$, and their nanocomposite are shown in Figure 4. Characteristic peaks of both PANi and Cloisite clay are present in the spectrum of their nanocomposite, PACN, which indicates the presence of clay in the nanocomposite. The FTIR spectrum of PANi confirmed that PANi is in the emeraldine form. From the FTIR spectrum of PACN, we can also observe that there is no specific change or shift of PANi characteristic peaks in the spectrum, which indicates that incorporation of clay does not affect the chemical structure of PANi.

The FTIR spectra for a range of PANi samples synthesized with oxidant (APS) concentrations of $0.1,0.2$, and $0.5 \mathrm{wt} \%$, respectively, showed that the oxidation state changed with oxidant concentration (shown in Figure 4). The absorption bands at around 1500 and $1600 \mathrm{~cm}^{-1}$ represent the benzenoid and quinoid functional groups, respectively, in PANi. The ratio of the heights of the two peaks $\left(1600: 1500 \mathrm{~cm}^{-1}\right)$ represents relative abundance of the two groups in the sample. The ratios were calculated and plotted in Figure 4. It is shown that as the concentration of the oxidant increased from 0.1 to $0.5 \%$, the ratio decreased slightly from 60 to $56 \%$. Comparison of the ratio of quinoid to benzenoid groups obtained for oxidant concentrations of 0.2 and $0.5 \%$ shows a slight increase of the quinoid group present, suggesting a slight increase in oxidation states of the PANi. Overall, increasing the oxidant concentration from 0.1 to $0.5 \%$, a $400 \%$ increase, resulted in only a slight decrease in the ratio from 60 to $56 \%$, an approximate $6.67 \%$ decrease. This phenomenon suggests an optimum oxidant concentration of $0.1 \%$ and indicates that the amount of oxidant used in the chemical synthesis of PANi plays an important role in determining its oxidation states. 


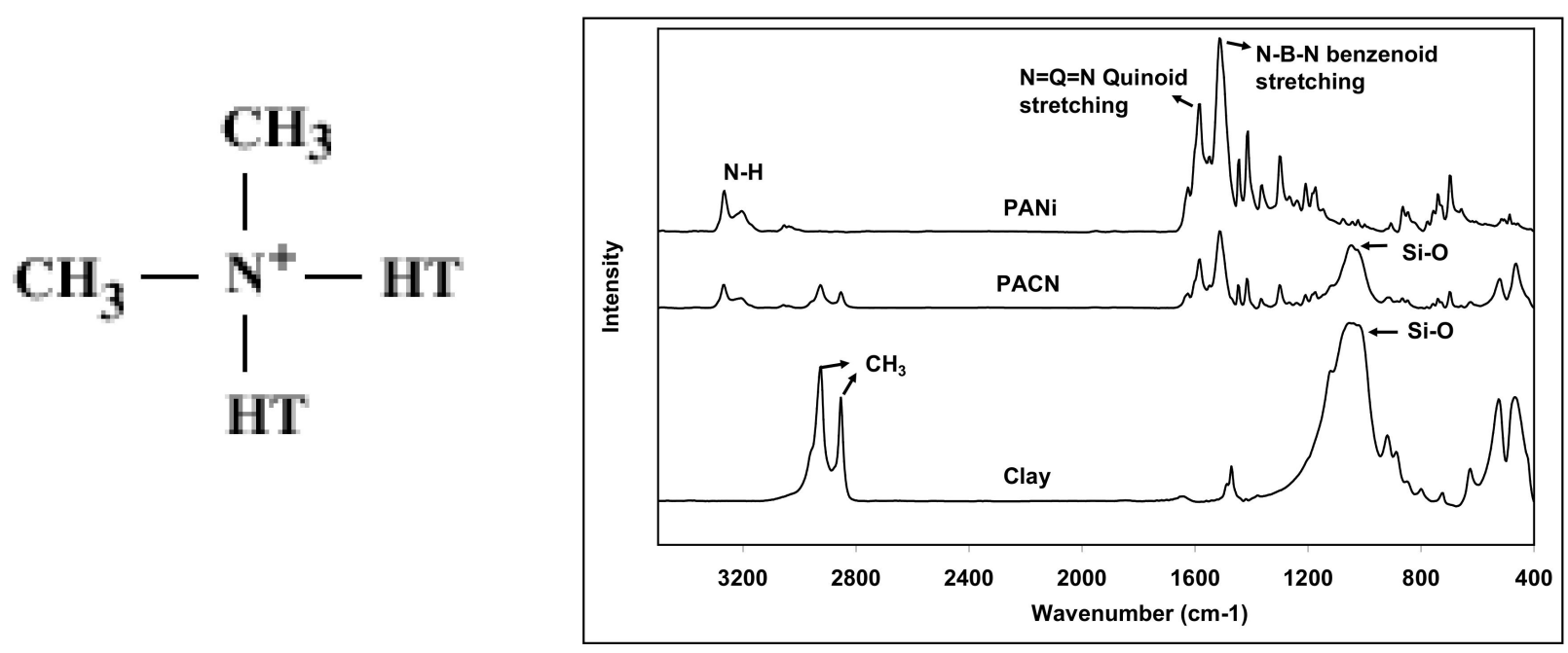

(a)

(b)

Figure 3. (a) Quaternary ammonium cation in 20 A clay gallery, where HT is hydrogenated tallow; the anion is $\mathrm{Cl}^{-}$. (b) FTIR spectra of PANi, clay, and PACN.

Table 1. Summary of FTIR absorption peaks of CLOISITE ${ }^{\circledR} 20$ A clay.

\begin{tabular}{cc}
\hline $\begin{array}{c}\text { Peak Position } \\
\left(\mathbf{c m}^{-\mathbf{1}} \mathbf{)}\right.\end{array}$ & Peak Assignment \\
2928 and 2854 doublet & $\mathrm{CH}_{2}$ asymmetric stretching $\left(2928 \mathrm{~cm}^{-1}\right)$ \\
and $\mathrm{CH}_{2}$ symmetric stretching \\
1637 & $\mathrm{H}-\mathrm{O}-\mathrm{H}$ bending \\
1474 & $\mathrm{CH}_{2}$ plane scissoring \\
798 & Silicate Si-O bond stretching \\
$450-600$ doublet & $\mathrm{CH}$ out of plane bending \\
\end{tabular}

Table 2. Summary of FTIR absorption peaks of PANi.

\begin{tabular}{cc}
\hline $\begin{array}{c}\text { Peak Position } \\
\left(\mathbf{c m}^{-\mathbf{1}}\right)\end{array}$ & Peak Assignment \\
\hline 3265 and 3200 doublet & Secondary amine \\
1584 & $\mathrm{~N}=\mathrm{Q}=\mathrm{N}$ quinoid ring stretching \\
1511 & $\mathrm{~N}=\mathrm{B}=\mathrm{N}$ benzenoid ring stretching \\
1300 & $\mathrm{~N}-\mathrm{H}$ deformation \\
850 & $\mathrm{C}-\mathrm{H}$ ring hydrogen \\
\hline
\end{tabular}

The FTIR spectra of the nanocomposites obtained at different oxidant concentrations (Figure 5) show that as the concentration of the oxidant increases, the ratio of characteristic polyaniline peaks (1600:1500) initially dropped from 75 to $50 \%$, as the oxidant concentration was increased from $0.1 \%$ to $0.5 \%$, but subsequently increased to $100 \%$ at an oxidant concentration of $0.8 \%$. At an oxidant concentration of $0.8 \%$, the 1600:1500 ratio increased sharply to about $100 \%$. This suggests that, at this particular point, the amount of quinoid group equals the amount of benzenoid group present in the nanocomposites. This result indicates that the oxidant concentration remarkably affects the resulting PANi oxidation states in PACN, and the trend is similar to that of pure PANi. 


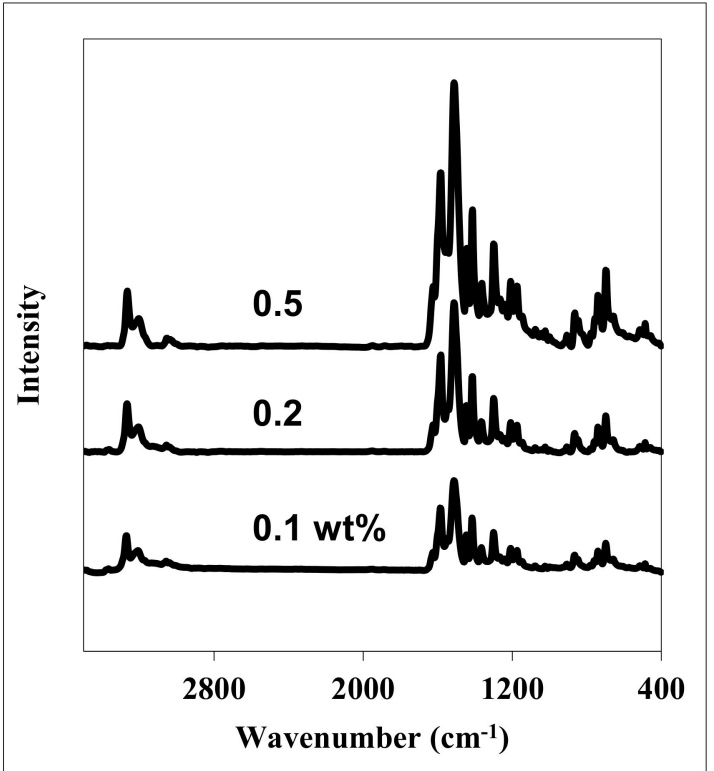

(a)

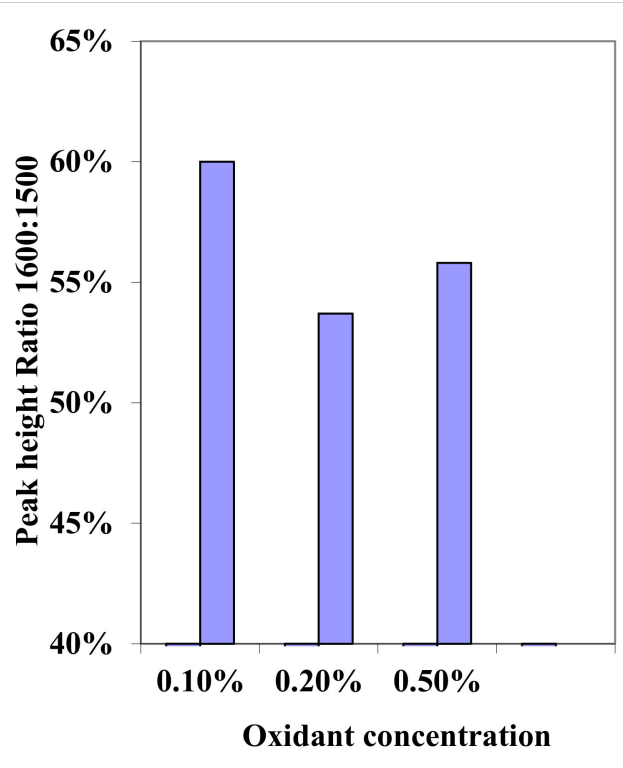

(b)

Figure 4. FTIR spectra of PANi at varying oxidant concentration (a) and ratio of 1600 and $1500 \mathrm{~cm}^{-1}$ peak heights $(\mathbf{b})$.

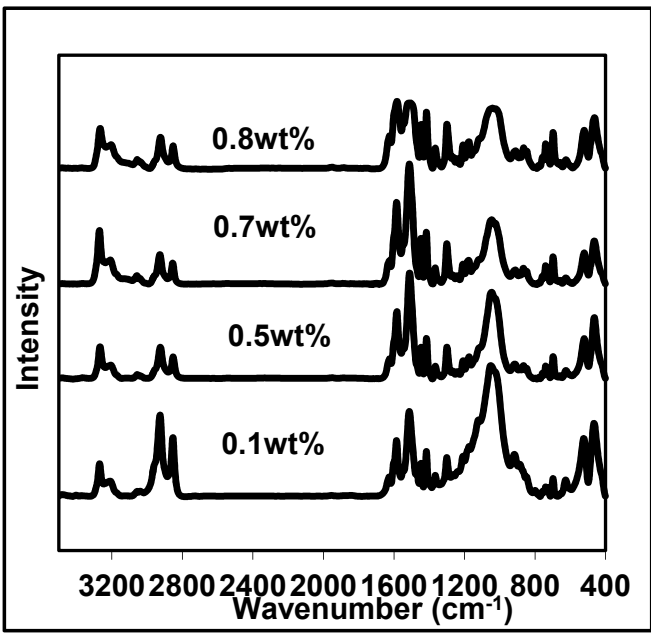

(a)

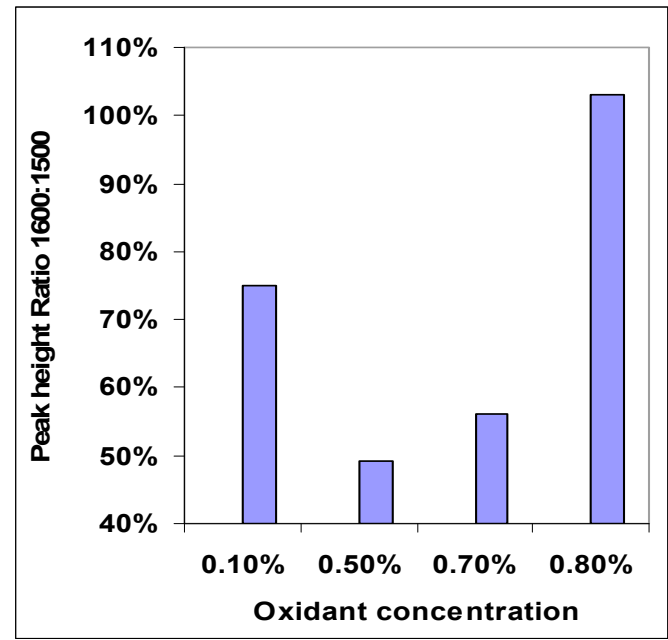

(b)

Figure 5. FTIR spectra of PACN synthesized at different oxidant concentration (a), and ratio of 1600 to $1500 \mathrm{~cm}^{-1}$ peak height $(\mathbf{b})$.

Figure 6 shows that as oxidant concentration increases, the ratio of characteristic polyaniline peaks $\left(1300 \mathrm{~cm}^{-1}\right.$, representing $\left.\mathrm{N}-\mathrm{H}\right)$ to clay peaks $\left(1054 \mathrm{~cm}^{-1}\right)$ significantly increases. It indicates that a greater amount of polymer is formed in the nanocomposites at higher oxidant concentrations, since the amount of aniline monomer and the amount of clay used in the synthesis were kept constant. This result agrees with the percentage of yield of these nanocomposite samples. As shown in Figure 6, the yield also increases as oxidant concentration increases. 


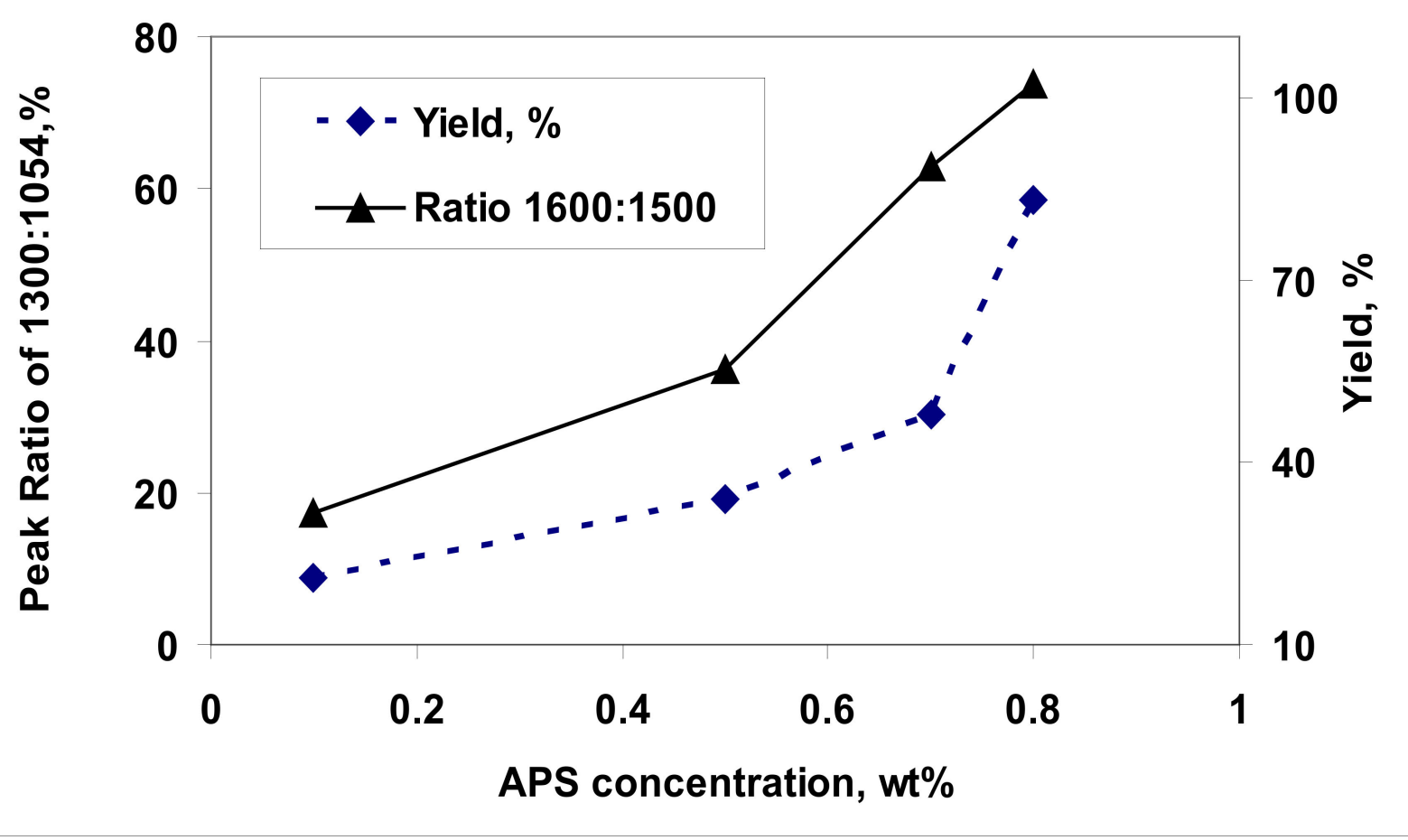

Figure 6. Variation of ratio of 1300 to $1054 \mathrm{~cm}^{-1}$ peak heights with APS concentration.

\subsection{Morphology}

The morphology of the nanocomposite powders was observed by using high-resolution SEM. The purpose of SEM study is to determine the structure of clay in the nanocomposite.

Organo-clay 20 A morphology was observed first under SEM, as shown in the micrographs in Figure 7. The 20 A clay consists of large, leaf-like, two-dimensional particles with a range of size distribution from about $1 \mu \mathrm{m}$ to $10 \mu \mathrm{m}$. This is in agreement with data provided by Southern Clay Product, Inc. Special attention is drawn to the thickness of the clay platelets, which is between 20 and $50 \mathrm{~nm}$. Apparently, a single particle consists of layers of silicate platelet $(\sim 1 \mathrm{~nm})$ stacked together. It is easy to note that there are about 20 to 50 layers of platelet in each particle.

Camphor sulfonic acid (CSA)-doped PACN and PANi were compared under SEM, and the micrographs were shown in Figure 8. In Figure 8a,b, PANi doped with CSA showed spherical particle morphology. Smaller particles $(\sim 10-50 \mathrm{~nm})$ are glued together to form bigger particles, while elongated particles are observed in the SEM micrograph of PACN-CSA. The elongated shape of these particles is an indication of pieces of clay covered with PANi. Because it is possiblly intercalated, these elongated particles do not show as high an aspect ratio as that for clay itself. For comparison, the same percentage of clay 20 A was mixed with PANi powder mechanically and observed under SEM (shown in Figure $9 a, b)$. It can be seen that the clay particles in the nanocomposites synthesized by in situ polymerization were not observed at the surface. However, for the mechanically mixed counterpart, exposed clay particles are easily seen on the surface. This suggests that, during in situ polymerization, the clay particles were covered by the polymer chains, and this phenomenon also indicates that clay has an affinity for PANi. PANi is possibly bonded to the clay surface by hydrogen bonding between amine groups at the chain end of PANi and the surface oxygen of clay. It was reported much earlier by Yariv et al. [34] that hydrogen bonding interaction occured between aniline and the silicate surface in montmorillonite clay. 


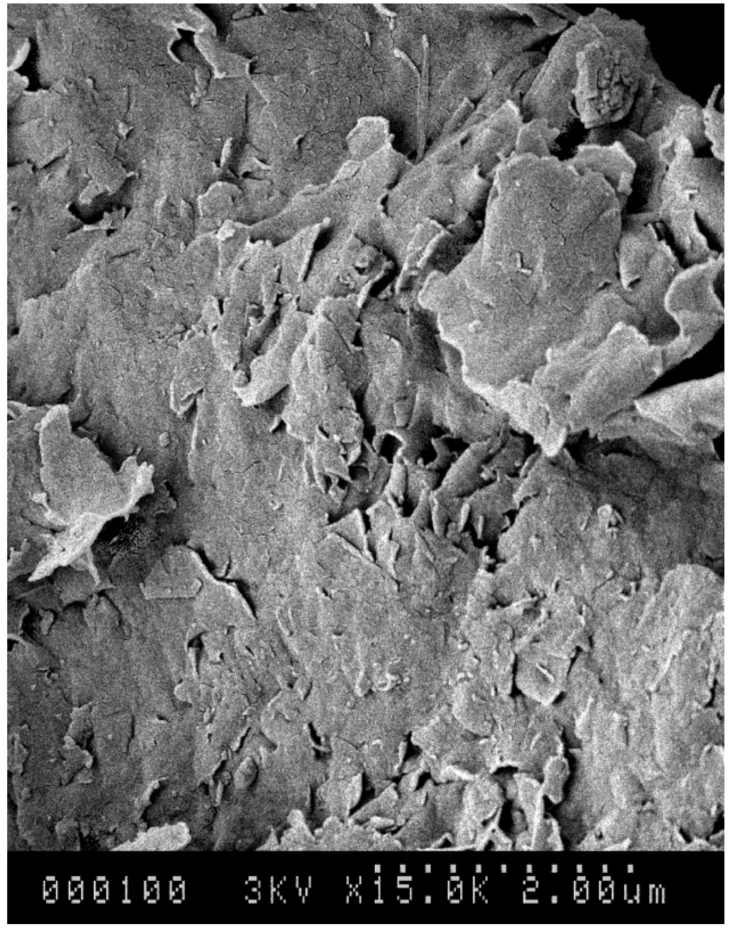

(a)

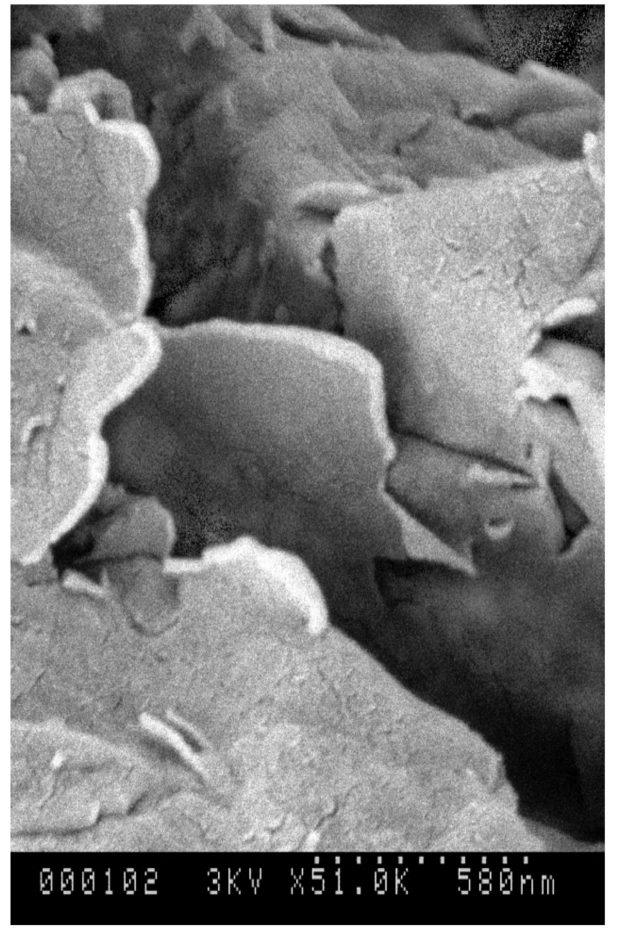

(b)

Figure 7. SEM micrograph of CLOISITE ${ }^{\circledR} 20$ A clay at two magnifications: $20 \mathrm{k}(\mathbf{a})$ and $51 \mathrm{k}(\mathbf{b})$.

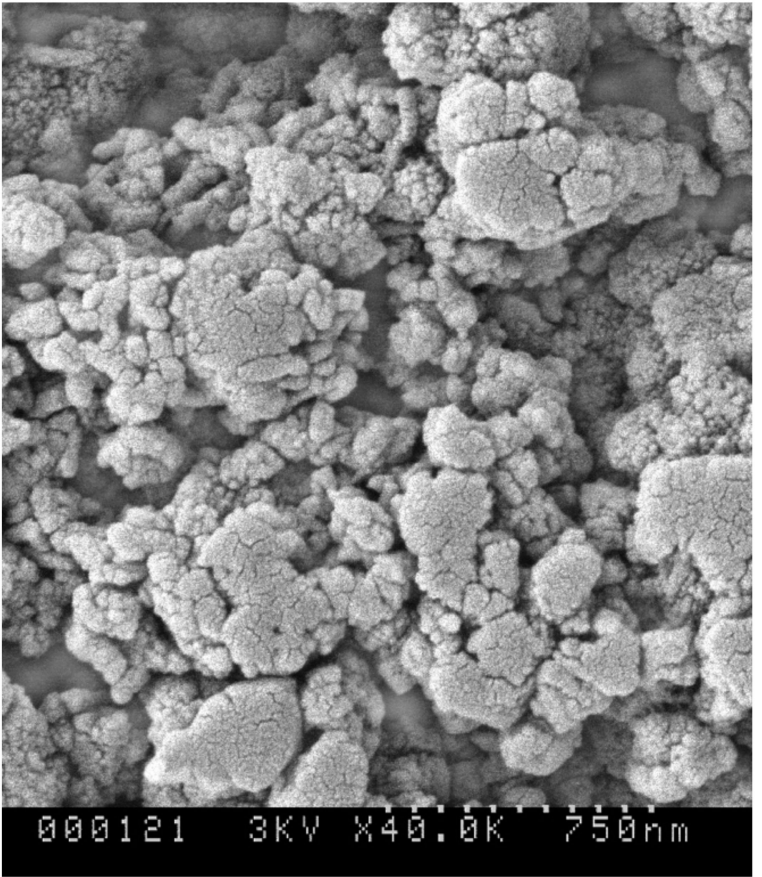

(a)

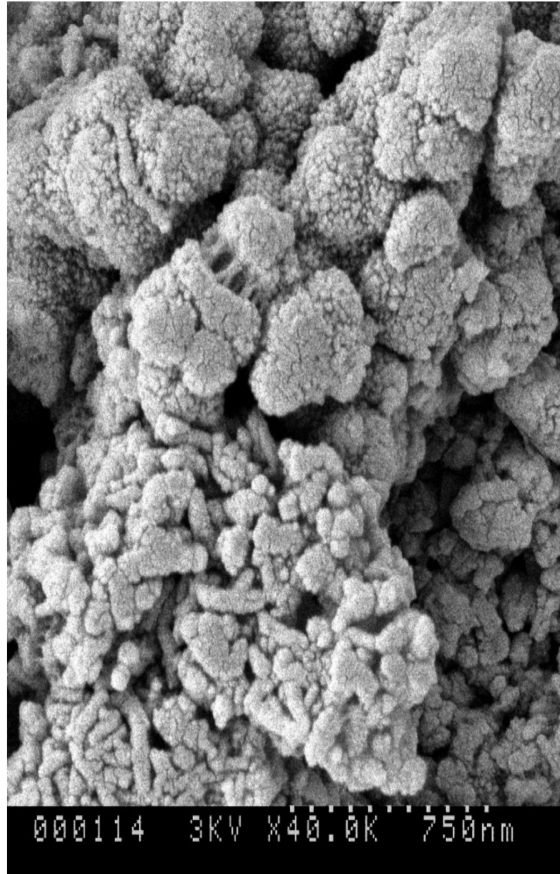

(b)

Figure 8. SEM micrographs of PANi -CSA (a) and PACN-CSA (b). 


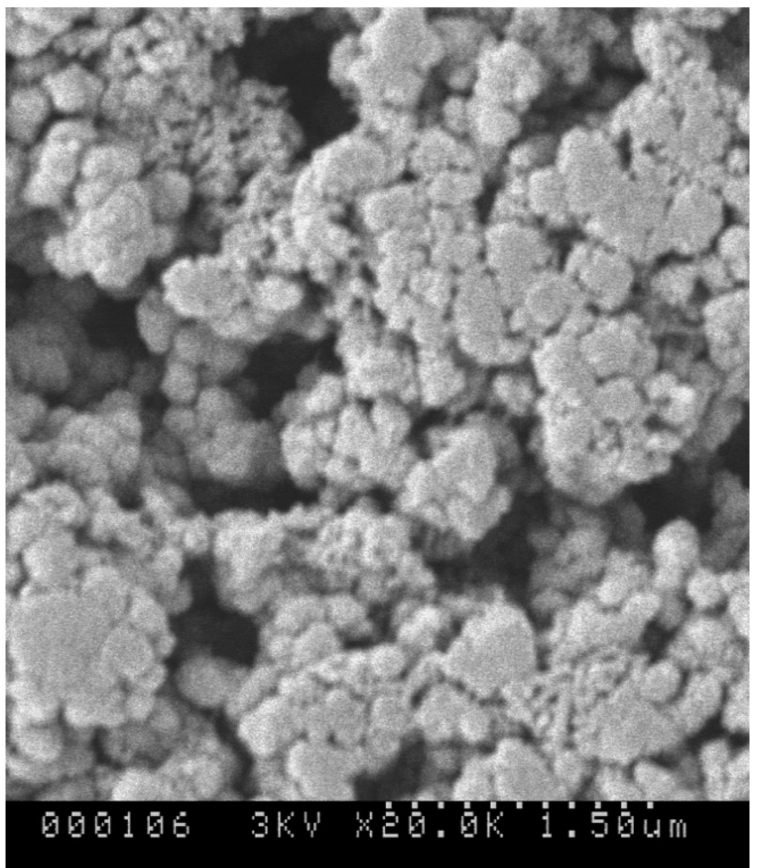

(a)

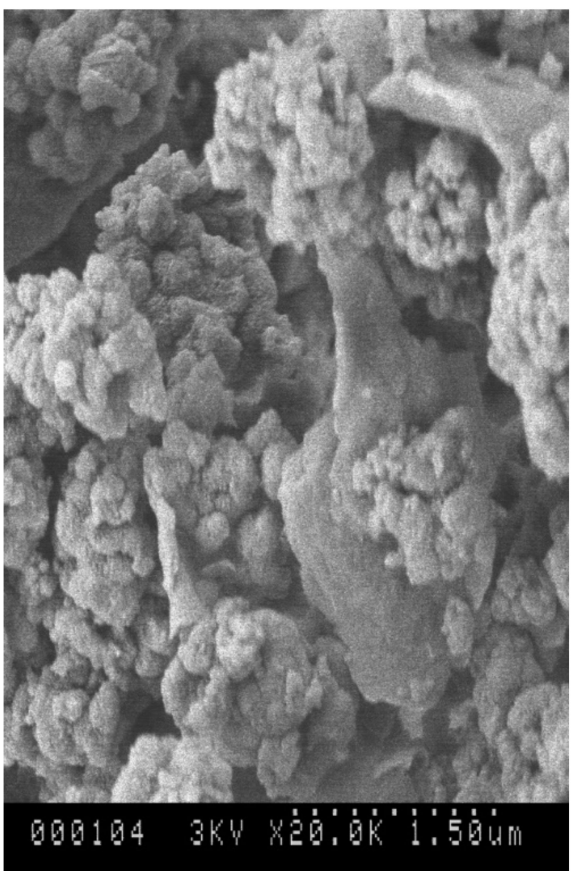

(b)

Figure 9. SEM micrographs of PACN-CSA (a) and mechanically mixed PANi-CSA and CLOISITE ${ }^{\circledR}$ 20 A clay (b).

Figure 10 shows a magnified SEM micrograph of the edge of one piece of clay particle in the undoped nanocomposite powder. At a magnification of $100 \mathrm{k}$, the cross-section view of the particle clearly shows a thickness of about $200 \mathrm{~nm}$, which is significantly higher than that of clay (thickness about $50 \mathrm{~nm}$ ), indicating that the clay is intercalated with PANi, and by calculation we can show that the d-spacing is expanded to about $44 \AA$. This result is in agreement with wide-angle $X$-ray diffraction and TEM results, which will be discussed in the following sections.

\subsection{Structure}

A wide-angle X-ray diffraction (WAXD) technique was used to study the structure of the powder samples of the nanocomposite. A low angle peak corresponds to the $d_{(001)}$ spacing, which is the distance of clay galleries. A shift of the $d_{(001)}$ spacing peak to a lower two theta angle denotes the expansion of the clay galleries. The disappearance of the peak in the WAXD-detectable two theta angle range indicates high degree of intercalation or exfoliation of the clay fillers. Figure 11 shows the XRD pattern of two kinds of clay used in this study: $\mathrm{Na}^{+}$clay and 20 A clay. $\mathrm{Na}^{+}$clay is pristine clay which contains $\mathrm{Na}^{+}$ cations inside the gallery to balance the excess negative charges, while $20 \mathrm{~A}$ is organically modified clay. CLOISITE ${ }^{\circledR} 20$ A clay contains dimethyl dehydrogenated tallow quaternary ammonium cations which impart clay with organophilic properties. It is shown in Figure 11 that $20 \mathrm{~A}$ has a lower angle d-spacing peak as compared to $\mathrm{Na}^{+}$clay, which indicates that 20 A clay gallery spacing is greater than that of $\mathrm{Na}^{+}$clay. XRD patterns of PACN nanocomposites synthesized using 20 A clay at different oxidant concentrations are shown in Figure 12. As shown from the XRD patterns, for all the PACN samples, the d-spacing peak has totally disappeared in the WAXD-detectable two theta angle range (shifted to lower angle), which suggests that the galleries of clay in the samples were expanded from $10.4 \AA$ to about $44.1 \AA$. The peak and corresponding $\mathrm{d}_{(001)}$ spacing values of clay samples and the nanocomposites are summarized in Table 3. The small peak at $2 \theta$ of $6.55^{\circ}$ for PACN samples with $0.5,0.7$, and $0.8 \mathrm{wt} \%$ oxidant concentration, respectively, corresponds to the PANi crystalline peak, as can be observed in the XRD pattern for PANi in Figure 12. 


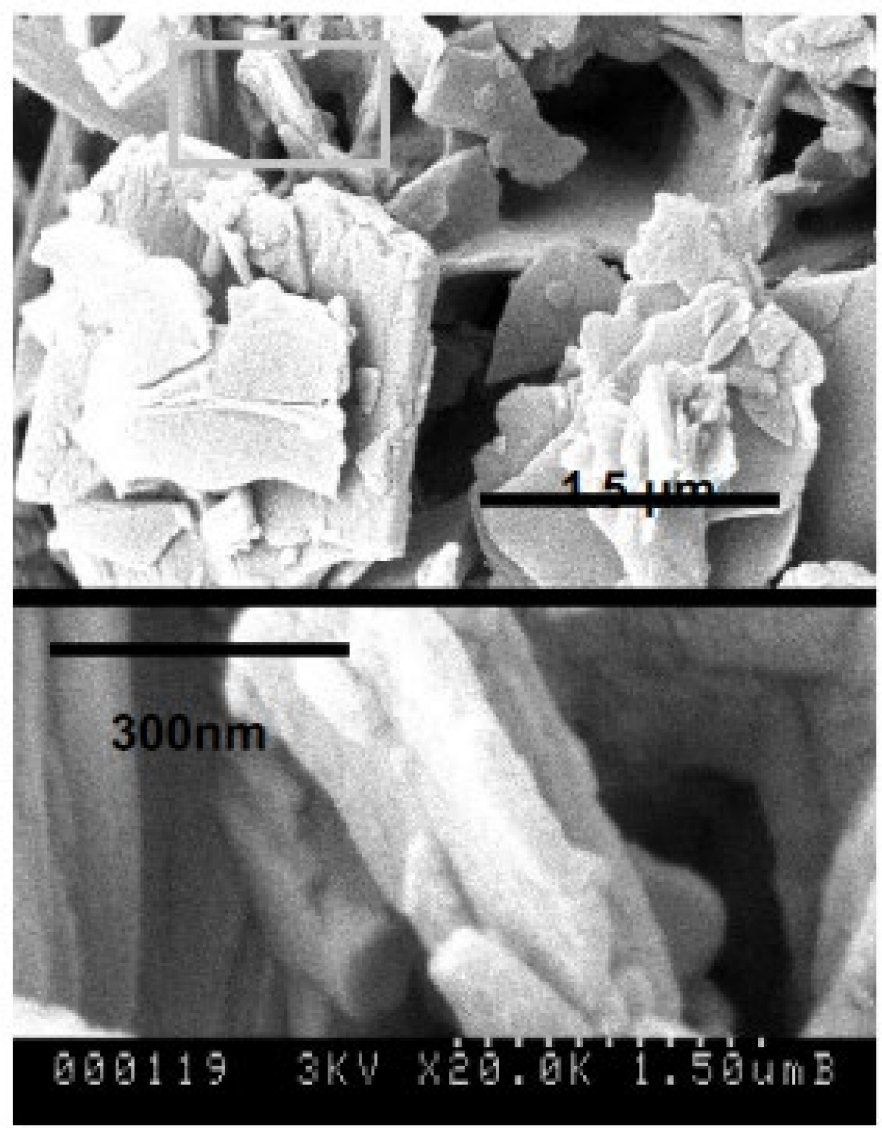

Figure 10. SEM micrograph of PACN powder.

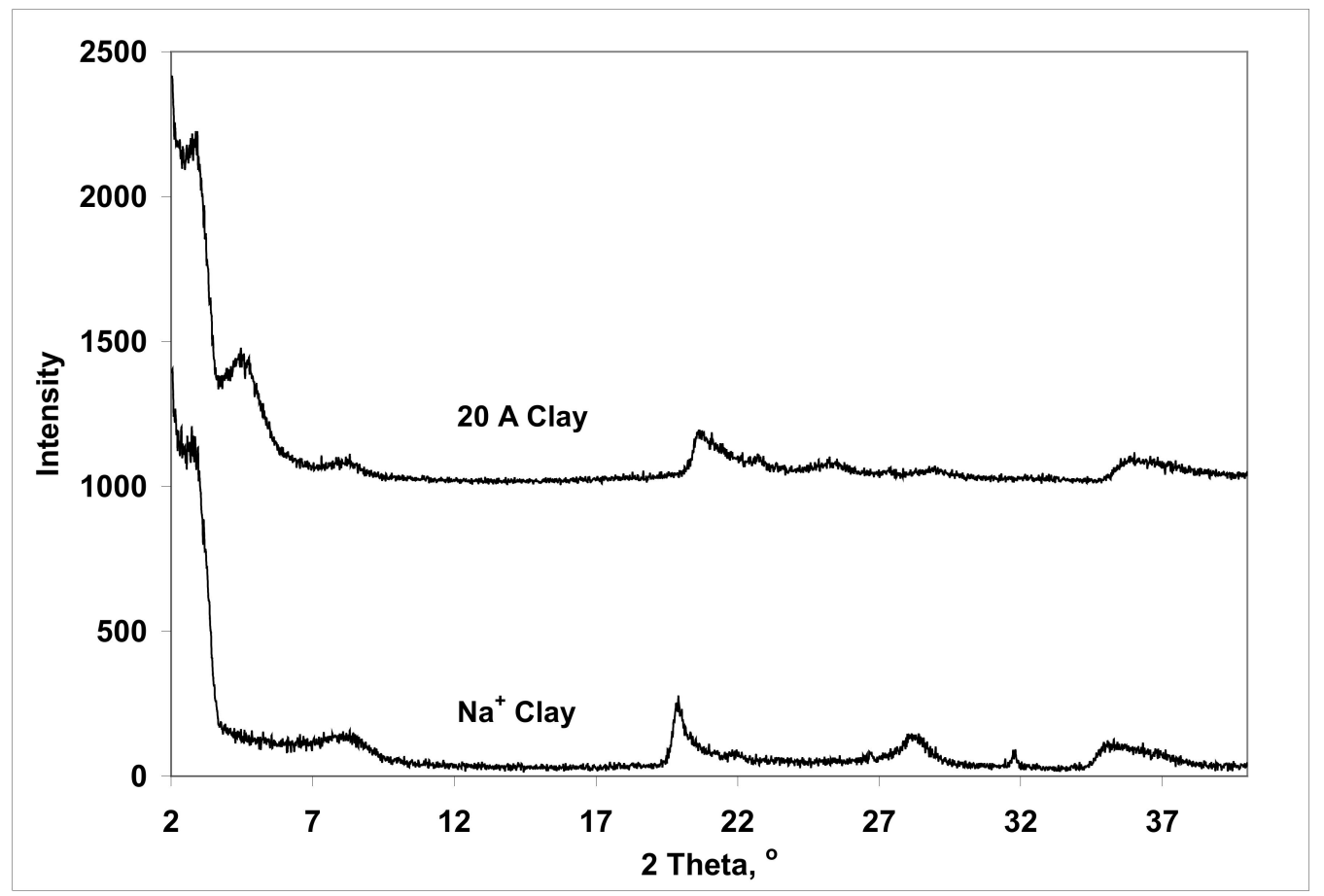

Figure 11. XRD patterns of CLOISITE ${ }^{\circledR} 20$ A clay and $\mathrm{Na}^{+}$clay. 


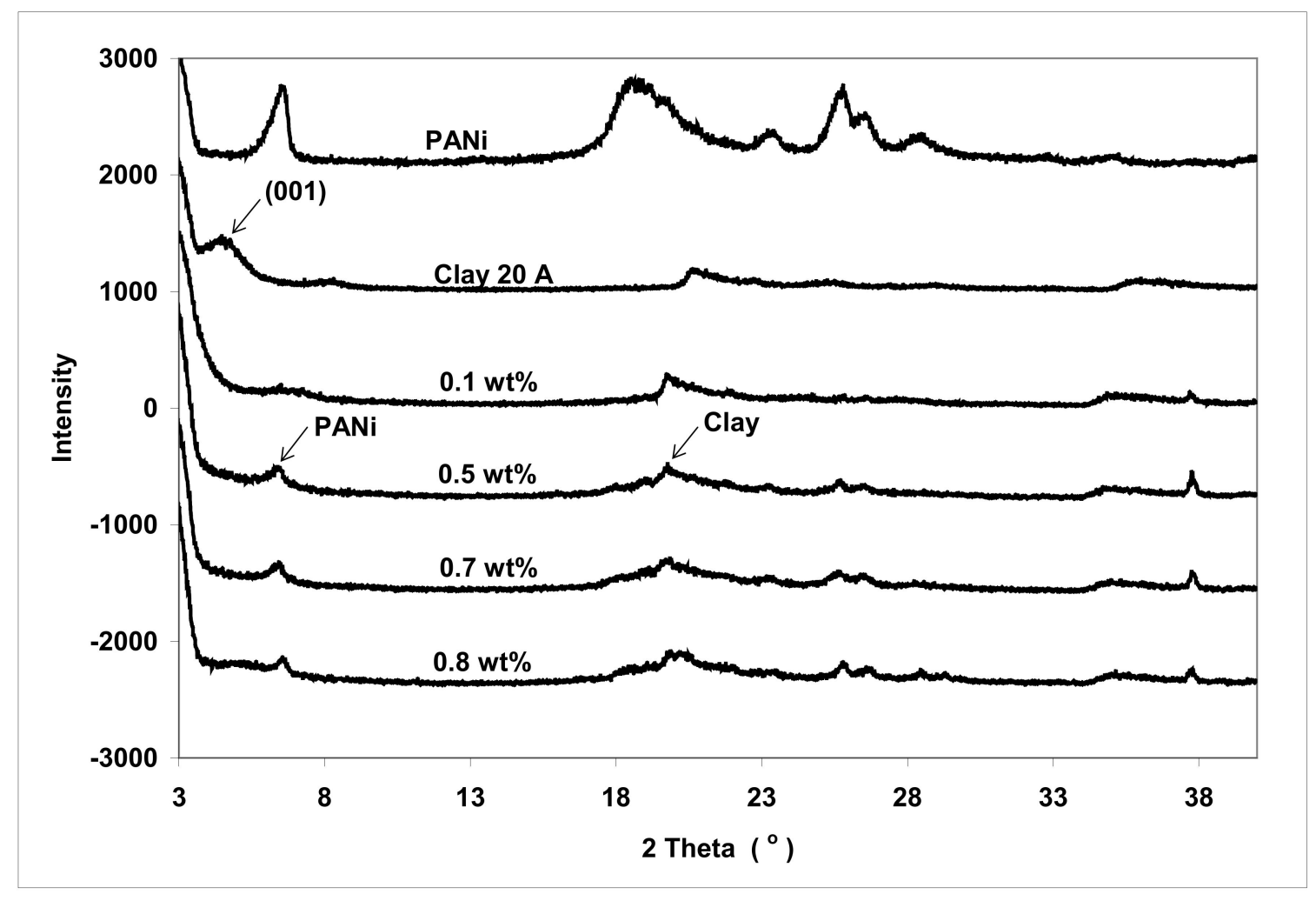

Figure 12. XRD patterns of PACN synthesized at varying oxidant concentrations.

Table 3. Summary of XRD data for $\mathrm{Na}^{+}$clay, 20 A clay, and PACN.

\begin{tabular}{ccc}
\hline Sample & 2 Theta Peak $\left(^{\circ}\right)$ & d-Spacing $(\AA)$ \\
\hline $\mathrm{Na}^{+}$clay & 8.49 & 10.4 \\
20 A clay & 4.57 & 19.3 \\
PACN\#1 & $>2$ & $>44.1$ \\
PACN\#4 & $>2$ & $>44.1$ \\
PACN\#5 & $>2$ & $>44.1$ \\
PACN\#6 & $>2$ & $>44.1$ \\
\hline
\end{tabular}

PANi-clay nanocomposites were also synthesized by using pristine clay. Figure 13 shows the XRD patterns and the schematic view of the corresponding structure of the nanocomposites. Results show that PANi is intercalated into the clay galleries.

To summarize, the XRD results show that the in situ polymerization method provides a gallery expansion of at least approximately $30 \AA$ of the clay particles. Further expansion is not detectable by wide-angle X-ray diffraction, and TEM results provide complementary information on the structure of clay. TEM micrographs provide a visual image of the expansion of clay galleries and total exfoliation. TEM micrographs of clay and PACN nanocomposites with clay loading of $20 \%$ are shown in Figure 14 . By observing the crosssection of a 20 A clay particle (Figure 14a), we can see parallel lines representing the layers of MMT (20 A) clay. From the TEM micrographs of PACN (Figure 14b), it can be seen that the distance between the lines is expanded to about $47 \AA$ or higher, which indicates intercalation of PANi into the MMT clay gallery. This finding is in agreement with the XRD data, which showed an expansion of the clay gallery to a distance of $44.7 \AA$ or higher. We can also observe platelets peeled off from the tactoids. Thus, both exfoliated clay and intercalated tactoids are present in the PACN nanocomposites. This result is in agreement with the findings of Yeh and colleagues [26]. 


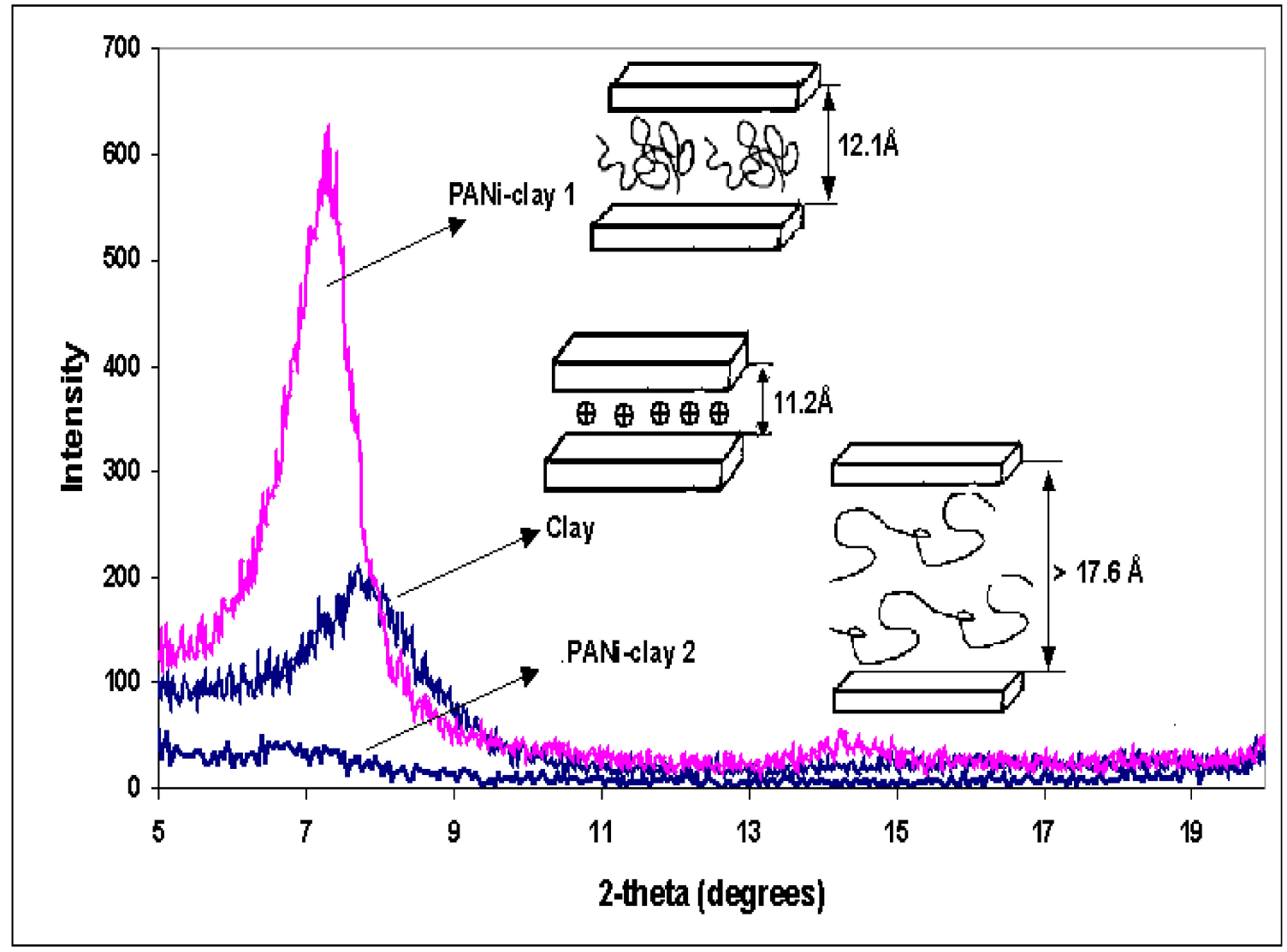

Figure 13. XRD patterns and schematic view of the corresponding structure of PACN synthesized by using $\mathrm{Na}^{+}$clay.

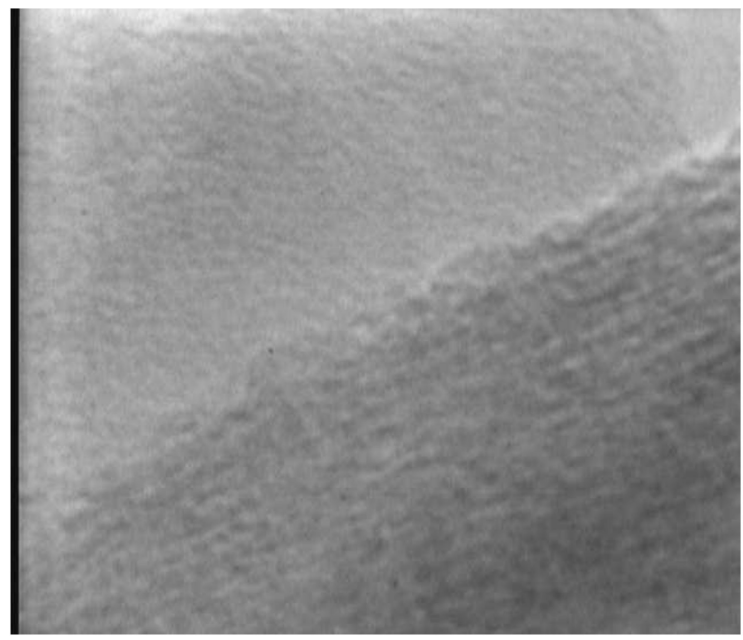

(a) $\times 2,500,000$

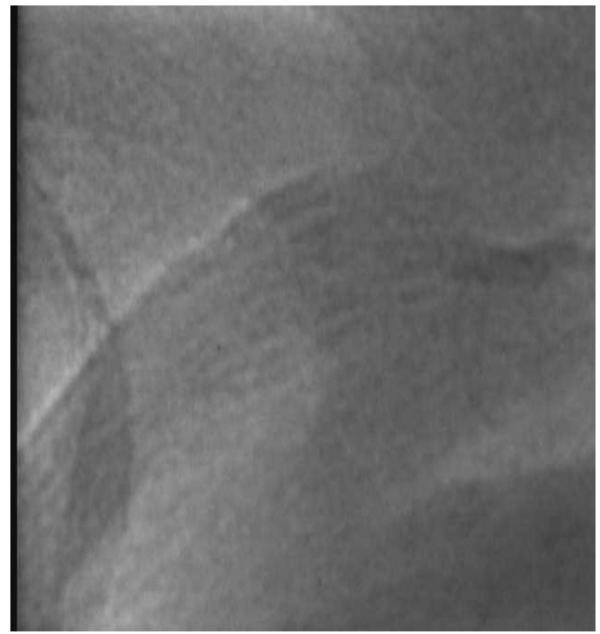

(b) $\times 1,000,000$

Figure 14. TEM micrographs of CLOISITE ${ }^{\circledR}$ clay 20 A (a) and PACN (b).

\subsection{Thermal Analysis}

Incorporation of inorganic fillers, especially layered silicate, is believed to improve various properties of the polymers remarkably, due to the nano-sized dispersion. Among them, enhancement of thermal properties is one that has been observed in many polymer nanocomposites. It was reported that incorporation of clay into epoxy resin significantly elevated the glass transition temperature and the degradation temperature of the pure polymer [1]. We studied the conducting polymer-clay system using thermal gravimetric 
analysis (TGA) and differential scanning calorimetry (DSC). Results showed enhanced thermal stability and elevated melting temperature, $\mathrm{T}_{\mathrm{m}}$, for the PACNs.

Figure 15 shows the TGA results for $20 \mathrm{~A}$ clay, $\mathrm{PANi}$, and their nanocomposites. An enhancement of thermal stability is clearly indicated by an increase of about $80{ }^{\circ} \mathrm{C}$ of degradation temperature, which is different from the findings of Yeh and colleagues [26]. The weight loss of PACN also decreased by about $25 \%$. Without the incorporation of clay, it is shown that PANi undergoes further weight loss after $800{ }^{\circ} \mathrm{C}$. The TGA curves for pure PANi synthesized at different oxidant concentrations are shown in Figure 16. The degradation temperature was taken as the temperatures corresponding to $10 \%$ weight loss, and the result is plotted in the embedded chart in Figure 16. As the oxidant concentration increases, PANi tends to degrade at lower temperatures. This result is in agreement with FTIR analysis, which indicated that a higher amount of quinoid group is present in PANi obtained at high oxidant concentration, since the quinoid structure is less stable than the benzenoid structure.

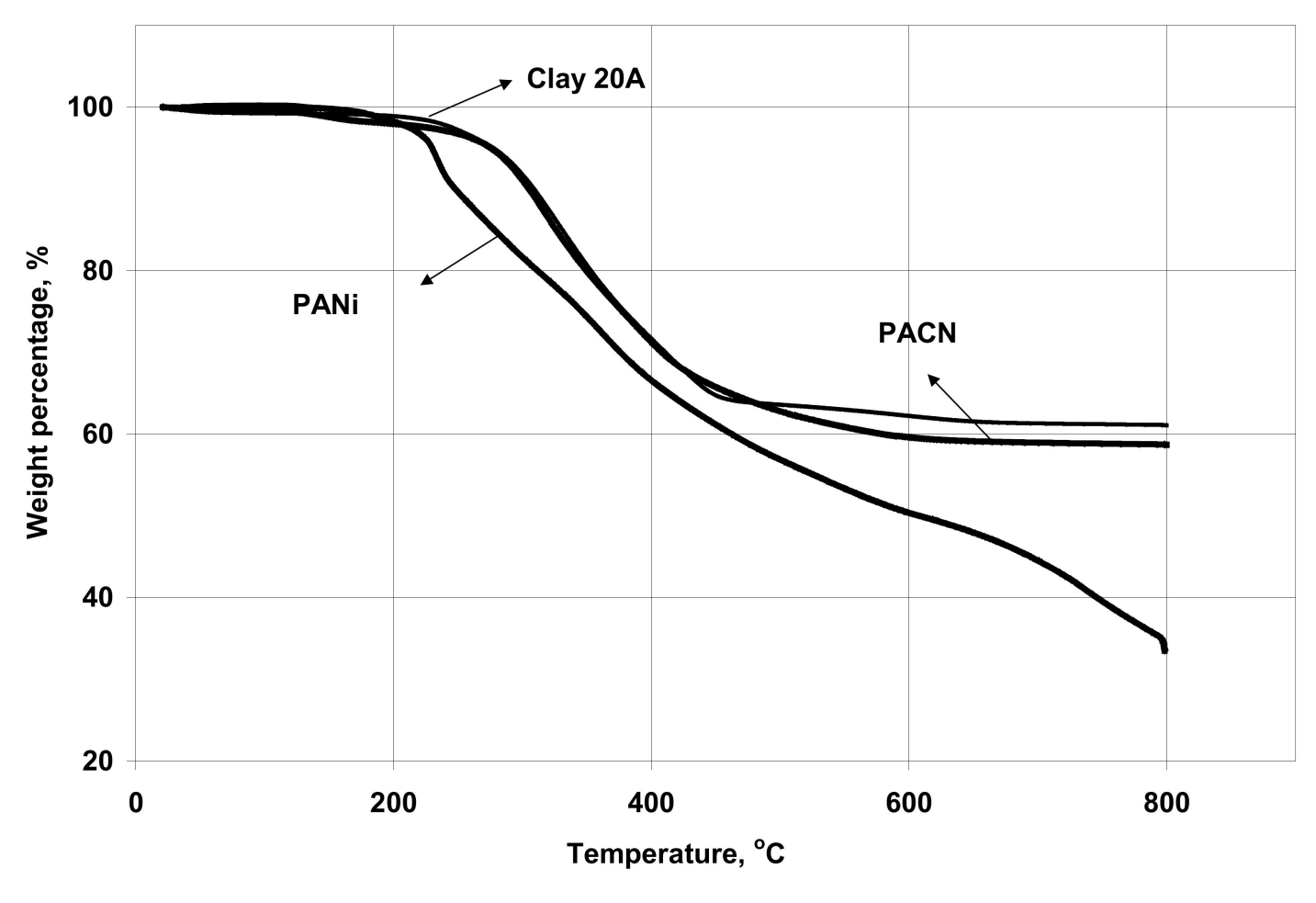

Figure 15. TGA traces for PANi, PACN, and CLOISITE ${ }^{\circledR}$ Clay 20 A.

It was found, from DSC study, that the PANi formed possessed crystalline structure, and a cold crystallization temperature and melting point typical of semicrystalline polymers are clearly shown in the DSC thermograms (see Figure 17). A decrease in the melting point was observed as the oxidant concentration increased, possibly due to increased restriction on PANi chain folding and close packing due to increased stiffness of the quinoid group (Figure 18). This assertion is supported by both FTIR and TGA results. A comparison of the DSC thermograms of PANi and PACN is shown in Figure 19. The melting point of PACN obtained at $0.5 \mathrm{wt} \%$ oxidant concentration was shown to be about $30^{\circ} \mathrm{C}$ higher than that for the neat PANi. 


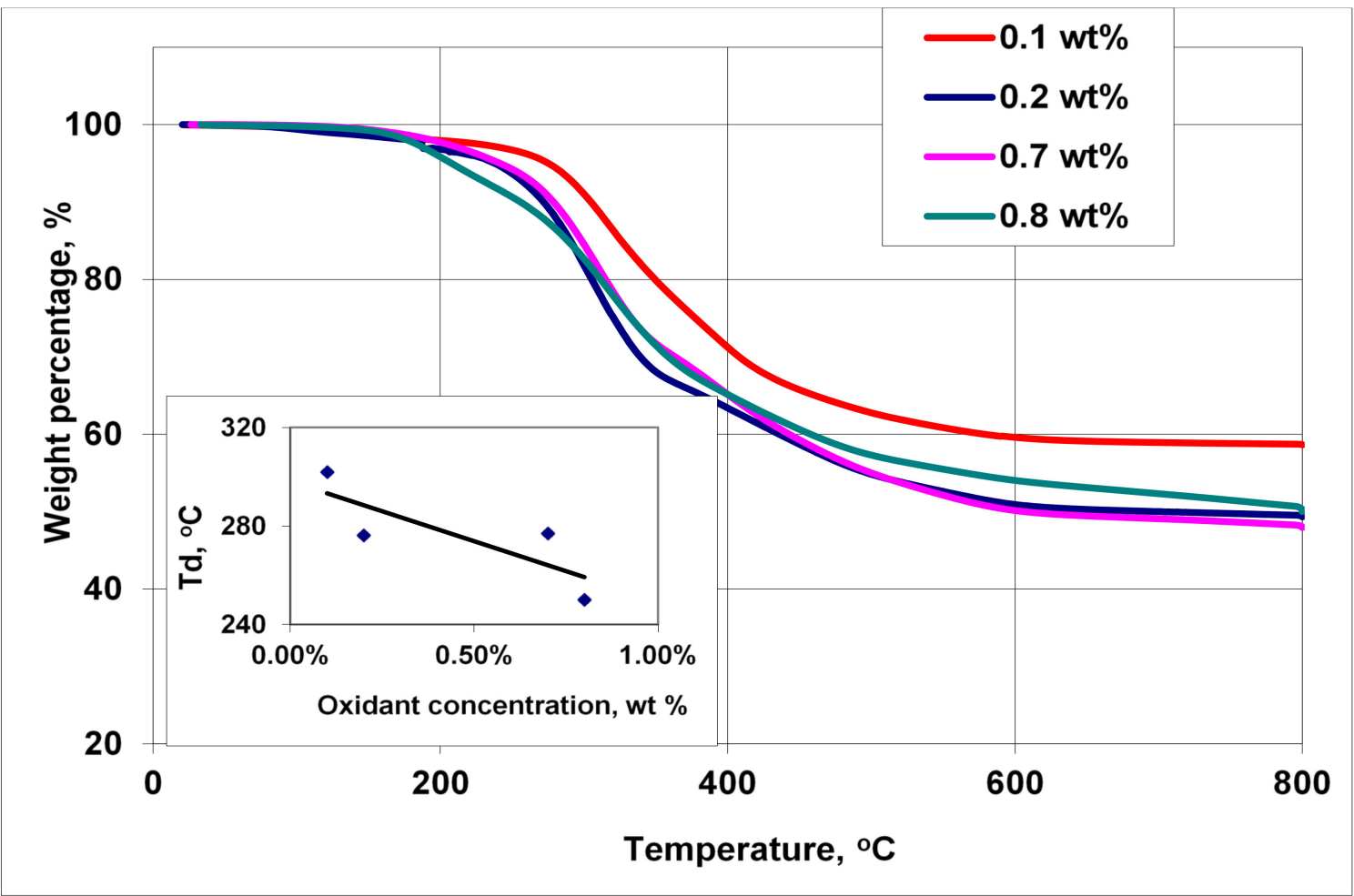

Figure 16. TGA traces for PACN synthesized at varying oxidant concentrations.

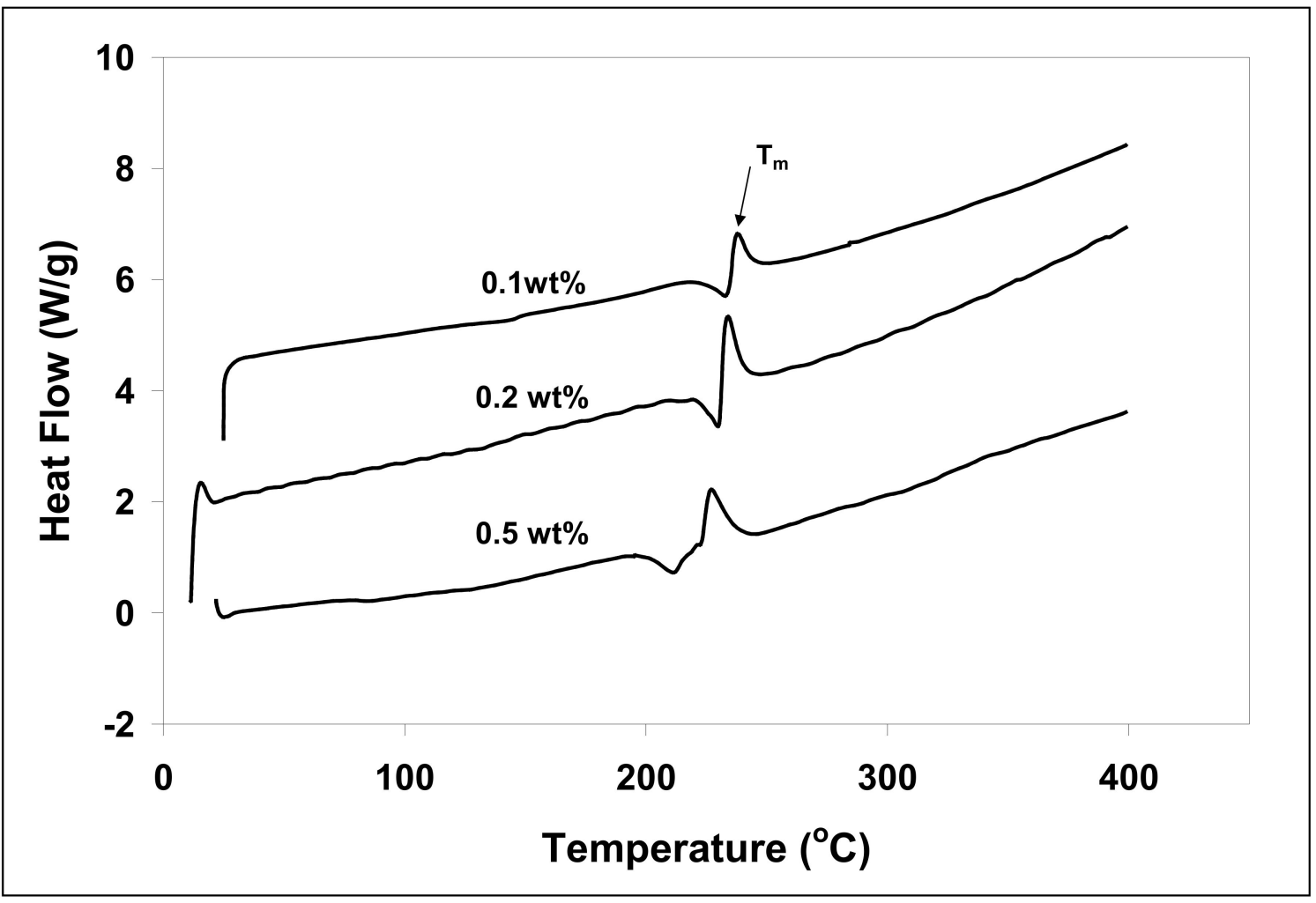

Figure 17. DSC thermograms of PANi synthesized by using varying oxidant concentrations. 


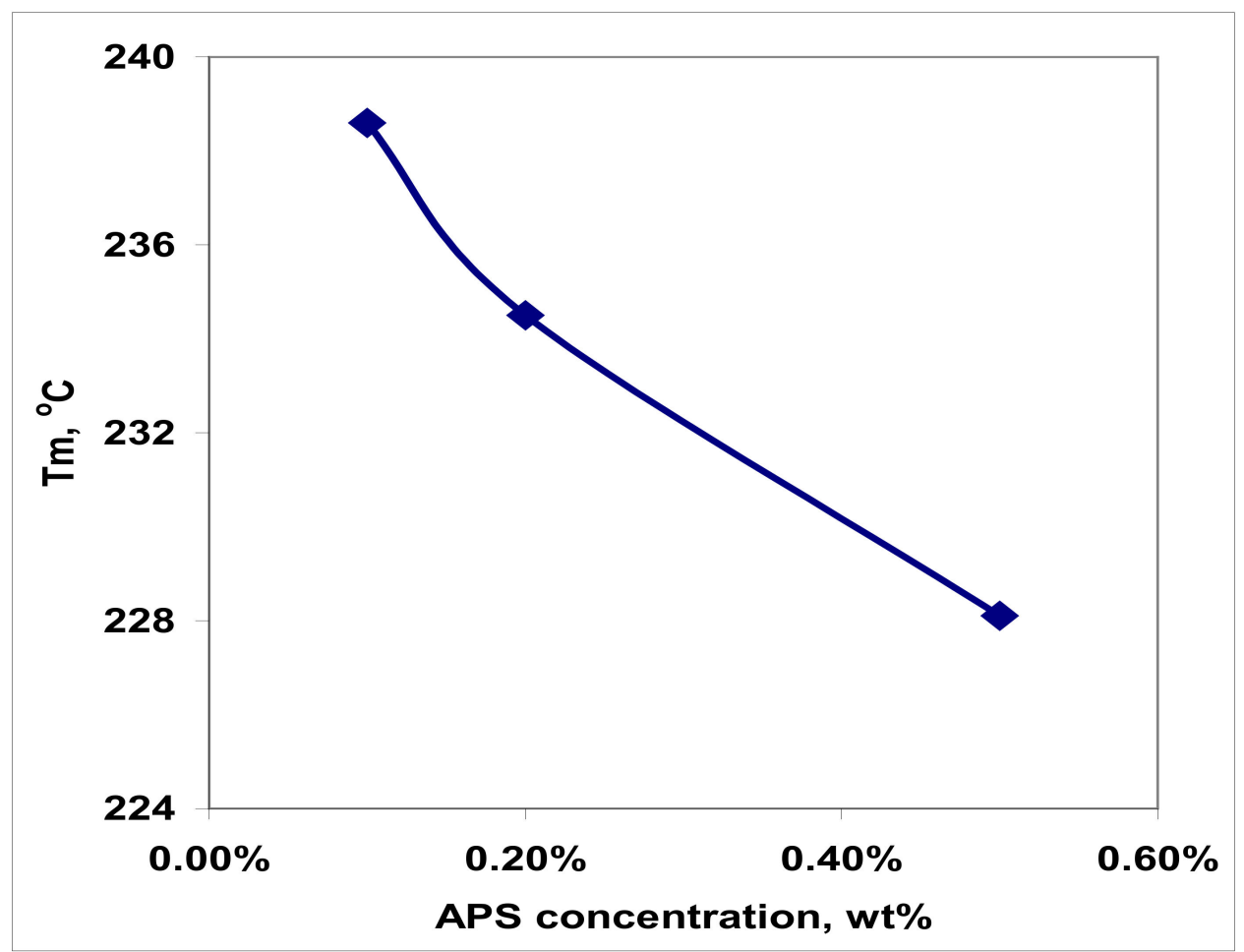

Figure 18. Effect of oxidant concentration on melting temperature of PANi.

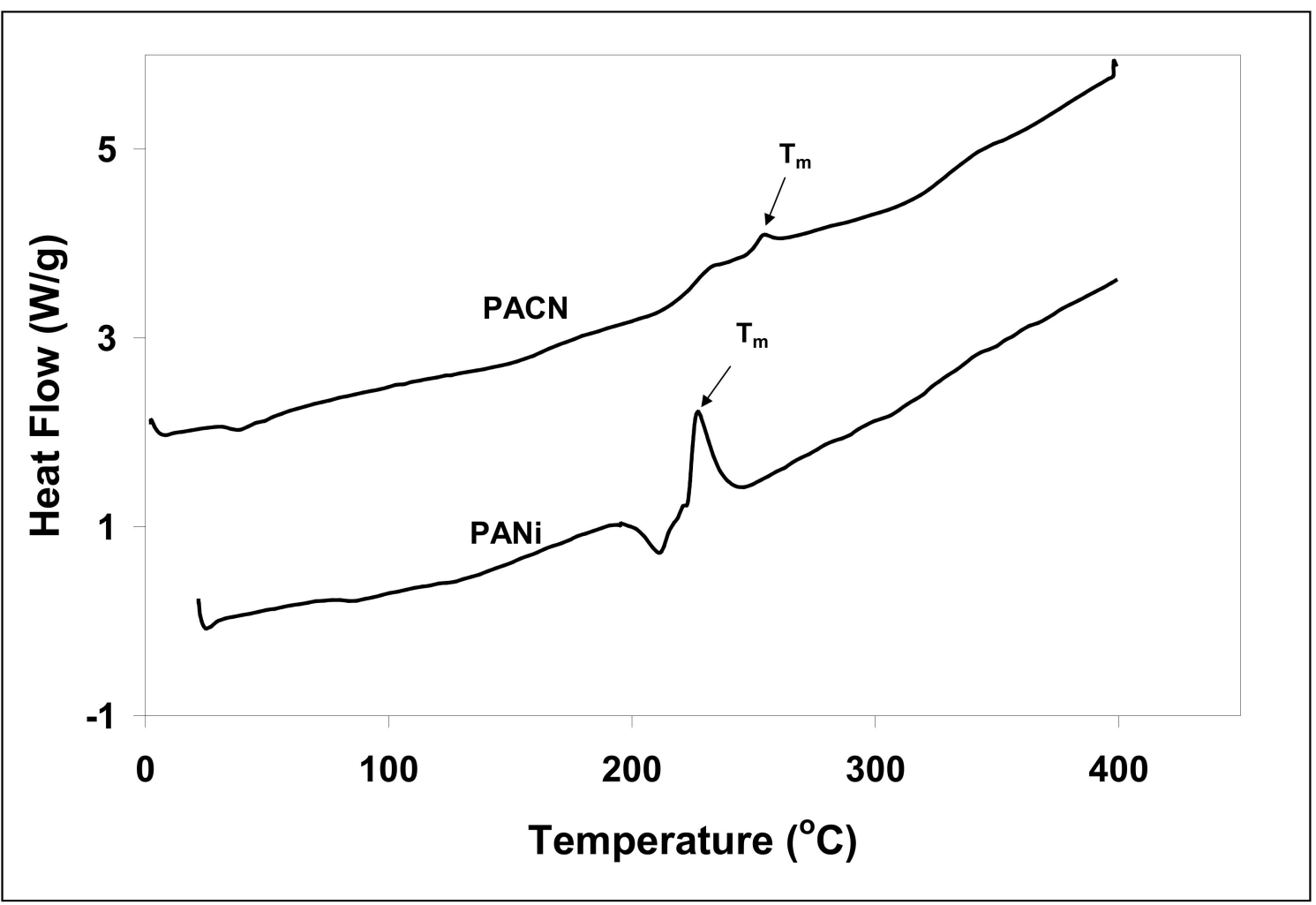

Figure 19. DSC thermograms of PANi and PACN synthesized by using the same oxidant conce-tration of $0.5 \mathrm{wt} \%$. 


\section{Conclusions}

PANi/MMT clay nanocomposites (PACN) were successfully synthesized by systematically varying the oxidant concentration and clay loading. TEM and XRD analysis showed that the PACN obtained in this study contain both intercalated and partially exfoliated clay platelets. The clay galleries for the PACN containing $20 \mathrm{wt} \%$ of MMT were expanded to about $47 \AA$, which is about $30 \AA$ higher than that for the neat MMT. FTIR analysis of both PANi and PACN showed that the oxidant concentration used in the synthesis greatly affected the oxidation states of PANi. Generally, increasing the oxidant concentration resulted in increasing quinoid structure of PANi; however, the polyaniline formed in this study is of the emeraldine state. DSC and XRD results confirmed that PANi prepared in this study is semicrystalline and that the melting point of PANi decreased with increasing oxidant concentration but increased with increasing MMT concentration. Specifically, the reinforcement of PANi with MMT resulted in an approximately $80^{\circ} \mathrm{C}$ increase in decomposition temperature. Incorporation of clay significantly increased the melting point of PANi. It is shown that for PACN containing $20 \mathrm{wt} \%$ MMT, prepared by using an oxidant concentration of $0.5 \mathrm{wt} \%$, the melting point of PACN was higher than that for neat PANi by about $30^{\circ} \mathrm{C}$.

Author Contributions: Conceptualization, J.O.I. and Y.Z.; methodology, Y.Z.; software, Y.Z;; validation, R.R., A.A. and Y.Z.; formal analysis, Y.Z.; investigation, J.O.I.; resources, R.V.; data curation, Y.Z.; writing-original draft preparation, Y.Z.; writing—review and editing, J.O.I., visualization, J.O.I.; supervision, J.O.I.; project administration, R.V.; funding acquisition, J.O.I. All authors have read and agreed to the published version of the manuscript.

Funding: This research was funded by The Ohio Aerospace Institute, OAI-CCRP program and the NRC/AFOSR Associateship program, AFRL/MLBT.

Institutional Review Board Statement: Not applicable.

Informed Consent Statement: Not applicable.

Data Availability Statement: Not applicable.

Acknowledgments: We gratefully acknowledge the Ohio Aerospace Institute (OAI) for supporting this research. The authors would like to acknowledge Xuemei Cui for her support in writing this article.

Conflicts of Interest: The authors declare no conflict of interest.

\section{References}

1. Chow, G.M.; Ovid'ko, I.A.; Tsakalakos, T. (Eds.) Nanostructured Films and Coatings; NATO Science Series, 3; High Technology; Springer Science \& Business Media: Berlin/Heidelberg, Germany, 2012; Volume 78.

2. Wijeratne, W.M.K.T.; Rajapakse, R.M.G.; Wijeratne, S.; Velauthamurty, K. Thermal properties of montmorillonite-polyaniline nanocomposites. J. Compos. Mater. 2011, 46, 1335-1343. [CrossRef]

3. Bekri-Abbes, I.; Srasra, E. Electrical and Dielectric Properties of Polyaniline and Polyaniline/Montmorillonite Nanocomposite Prepared by Solid Reaction Using Spectroscopy Impedance. J. Nanomater. 2015, 2015, 516902. [CrossRef]

4. Krishnamoorti, R.; Vaia, R.A.; Giannelis, E.P. Structure and Dynamics of Polymer-Layered Silicate Nanocomposites. Chem. Mater. 1996, 8, 1728. [CrossRef]

5. Burnside, S.D.; Giannelis, E.P. Nanostructure and Properties of Polysiloxane-Layered Silicate Nanocomposites. J. Polym. Sci. B 2000, 38, 1595. [CrossRef]

6. Vaia, R.A.; Giannelis, E.P. Lattice Model of Polymer Melt Intercalation in Organically-Modified Layered Silicates. Machomolecules 1997, 30, 7990-7999. [CrossRef]

7. LeBaron, P.C.; Wang, Z.; Pinnavaia, T.J. Polymer-Layered Silicate Nanocomposites: An Overview. Appl. Clay Sci. 1999, 15, 11-29. [CrossRef]

8. Kornmann, X.; Lindberg, H.; Berglund, L.A. Synthesis of epoxy-clay nanocomposites: Influence of the Nature of the Clay on Structure. Polymer 2001, 42, 1303-1310. [CrossRef]

9. Lan, T.; Kaviratna, P.D.; Pinnavaia, T.J. Epoxy Self-polymerization in Smectite Clays. J. Phys. Chem. Solids 1996, 57, 1005-1010. [CrossRef]

10. Fong, H.; Vaia, R.A.; Sanders, J.H.; Lincoln, D.; Vreugdenhil, A.J.; Liu, W.; Bultman, J.; Chen, C. Self Passivation of Polymer Layered Silicate Nanocomposites. Chem. Mater. 2001, 13, 4123-4129. [CrossRef] 
11. Wu, T.M.; Liao, C.S. Polymorphism in Nylon 6/Clay Nanocomposites. Macromol. Chem. Phys. 2000, 201, 2820-2825. [CrossRef]

12. Wu, Z.; Zhou, C.; Qi, R.; Zhang, H. Synthesis and Characterization of Nylon 1012/Clay Nanocomposite. J. Appl. Polym. Sci. 2002, 83, 2403-2410. [CrossRef]

13. Delozier, D.M.; Orwoll, R.A.; Cahoon, J.F.; Johnston, N.J. Preparation and Characterization of Polyimide/Organoclay Nanocomposites. Polymer 2002, 43, 813-822. [CrossRef]

14. Liang, Z.; Yin, J.; Xu, H. Polyimide/Montmorillonite Nanocomposites Based on Thermally Stable Rigid-Rod Aromatic Amine Modifiers. Polymer 2003, 44, 1391-1399. [CrossRef]

15. Chen, T.K.; Tien, T.I.; Wei, K.H. Synthesis and Characterization of Novel Segmented Polyurethane/Clay Nanocomposites via Poly (E-caprolactone)/Clay. J. Polym. Sci. Part A Polym. Chem. 1999, 37, 2225-2233. [CrossRef]

16. Kodaire, P.; Kalgaonkar, R.; Hambir, S.; Bulakh, N.; Jog, J.P. PP/Clay Nanocomposites: Effect of Clay Treatment on Morphology and Dynamic Mechanical Properties. J. Appl. Polym. Sci. 2001, 81, 1786-1792.

17. Shakoor, A.; Rizvi, T.Z.; Farooq, H.U.; Hassan, N.; Majid, A.; Saeed, M.; Farooq, M. Structural and Electrical Properties of Doped Polypyrrole and its Composite with Montmorillonite Clay. Polym. Sci. Ser. A 2013, 55, 279-284. [CrossRef]

18. Tokarsky, J.; Peikertova, P.; Kulhankova, L.; Kutlakova, K.M.; Neuwirthova, L. Functional Nanocomposites of Montmorillonite with Conducting Polyaniline. Clay Miner. 2015, 50, 341-351. [CrossRef]

19. Kazim, S.; Ahmad, S.; Pfleger, J.; Plestil, J.; Joshi, Y.M. Polyaniline-Sodium Montmorillonite ClayNanocomposites: Effect of Clay Concentration on Thermal, Structural and Electrical Properties. J. Mater. Sci. 2012, 47, 420-428. [CrossRef]

20. Theng, B.K.G. The Chemistry of Clay-Organic Reactions; Adam Hilger Ltd., Rank Precision Industries: London, UK, 1974.

21. Zhu, Y.; Iroh, J.O. Electrochemical Synthesis of Polyaniline Films in the Presence of Inorganic Fillers and Their Effect on Corrosion Protection of Al 2024-T3. J. Adv. Mater. 2002, 34, 16-21.

22. Kim, J.W.; Liu, F.; Choi, H.J.; Hong, S.H.; Joo, J. Intercalated Polypyrrole/Na+-Montmorillonite Nanocomposite Via An Inverted Emulsion Pathway Method. Polymer 2003, 44, 289-293. [CrossRef]

23. Wu, Q.; Xue, Z.; Qi, Z.; Wang, F. Synthesis and Characterization of PAn/Clay Nanocomposite with Extended Chain Conformation of Polyaniline. Polymer 2000, 41, 2029-2032. [CrossRef]

24. Kim, B.H.; Jung, J.H.; Hong, S.H.; Kim, J.W.; Choi, H.J.; Joo, J. Physical Characterization of Emulsion Intercalated Polyaniline-Clay Nanocomposite. Curr. Appl. Phys. 2001, 1, 112-115. [CrossRef]

25. Kim, B.; Jung, J.; Hong, S.; Joo, J.; Epstein, A.J.; Mizoguchi, K.; Kim, J.W.; Choi, H.J. Nanocomposites of Polyaniline and Na+-Montmorillonite Clay. Macromolecules 2002, 35, 1419-1423. [CrossRef]

26. Yeh, J.; Liou, S.; Lai, C.; Wu, P.; Tsai, T. Enhancement of Corrosion Protection Effect in Polyaniline Via the Formation of Polyaniline-Clay Nanocomposite Materials. Chem. Mater. 2001, 13, 1131-1136. [CrossRef]

27. Jia, W.; Segal, E.; Kornemandel, D.; Lamhot, Y.; Narkis, M.; Siegmann, A. Polyaniline-DBSA/Organophilic Clay Nanocomposites: Synthesis and Characterization. Synth. Met. 2002, 128, 115-120. [CrossRef]

28. Zeng, Q.H.; Wang, D.Z.; Yu, A.B.; Lu, G.Q. Synthesis of Polymer-Montmorillonite Nanocomposites by In-situ Intercalation Polymerization. Nanotechnology 2002, 13, 549-553. [CrossRef]

29. Yamabe, K.; Goto, H. Synthesis and Surface Observation of Montmorillonite/Polyaniline Composites. J. Compos. Sci. 2018, 2, 15 [CrossRef]

30. Zehhaf, A.; Morallon, E.; Benyoucef, A. Polyaniline/Montmorillonite Nanocomposites Obtained by In-situ Intercalation and Oxidative Polymerization in Cationic Modified-Clay (Sodium, Copper and Iron). J. Inorg. Organomet. Polym. Mater. 2013, 23, 1485-1491. [CrossRef]

31. Kim, J.W.; Kim, S.G.; Choi, H.J.; Jhon, M.S. Synthesis and Electrorheological Properties of Polyaniline-Na ${ }^{+}-\mathrm{Montmorillonite}^{-}$ Suspensions. Macromol. Rapid Commun. 1999, 20, 450-452. [CrossRef]

32. Park, J.H.; Lim, Y.T.; Park, O.O. New Approach to Enhance the Yield Stress of Electro-Rheological Fluids by Polyaniline-Coated Layered Silicate Nanocomposites. Macromol. Rapid Commun. 2001, 22, 616-619. [CrossRef]

33. Lu, J.; Zhao, X. Electrorheological Properties of a Polyaniline-Montmorillonite Clay Nanocomposite Suspension. J. Mater. Chem. 2002, 12, 2603-2605. [CrossRef]

34. Yariv, S.; Heller, L.; Kaufherr, N. Effect of Acidity in Montmorillonite Interlayers on the Sorption of Aniline Derivatives. Clays Clay Miner. 1969, 17, 301-308. [CrossRef] 